\title{
A Quantitative Assay Using Mycelial Fragments to Assess Virulence of Mycosphaerella fijiensis
}

\author{
Bruno Giuliano Garisto Donzelli and Alice C. L. Churchill
}

Boyce Thompson Institute for Plant Research, Ithaca, NY 14853-1801.

Current address of B. Giuliano Garisto Donzelli and A. C. L. Churchill: Department of Plant Pathology, Federal Plant, Soil, and Nutrition Laboratory, Tower Road, Cornell University, Ithaca, NY 14853.

Accepted for publication 20 March 2007.

\begin{abstract}
Donzelli, B. G. G, and Churchill, A. C. L. 2007. A quantitative assay using mycelial fragments to assess virulence of Mycosphaerella fijiensis. Phytopathology 97:916-929.

We describe a method to evaluate the virulence of Mycosphaerella fijiensis, the causal agent of black leaf streak disease (BLSD) of banana and plantain. The method is based on the delivery of weighed slurries of fragmented mycelia by camel's hair brush to 5-by-5-cm areas on the abaxial surface of banana leaf blades. Reliable BLSD development was attained in an environmental growth chamber with stringent lighting and

be tested on each leaf and plant, which is critical for comparing the virulence of numerous strains concurrently. Image analysis software was used to measure the percentage of each inoculated leaf section showing BLSD symptoms over time. We demonstrated that the level of disease of four isolates was correlated with the weight of the mycelium applied and relatively insensitive to the degree of fragmentation of hyphae. This is the first report demonstrating that weighed mycelial inoculum, combined with image analysis software to measure disease severity, can be used to quantitatively assess the virulence of $M$. fijiensis under rigorously controlled environmental conditions.
\end{abstract} humidity controls. By localizing inoculum onto small areas of large leaves, we achieved a dramatic increase in the number of strains that can
Additional keywords: black Sigatoka, conidia, Musa spp., virulence assay.
Mycosphaerella fijiensis (M. Morelet) (anamorph: Pseudocercospora fijiensis (M. Morelet) Deighton) (48) is the causal agent of black leaf streak disease (BLSD), also known as black Sigatoka, the most damaging and economically important disease of banana and plantain (Musa spp.) worldwide (11). This leaf pathogen is an increasing threat in all areas where Musa spp. are grown, destroying the photosynthetic capacity of banana leaves and causing reduced yield and premature ripening of the fruit. When BLSD is present, banana production can drop by $50 \%$ or more $(29,35,42,45,54)$. Fungicidal control of BLSD in Central America is responsible for at least $27 \%$ of the retail price of bananas $(53,55,57)$, with expenses totaling US $\$ 400$ to 1,400 per hectare per year $(2,3,42,44)$ due to the 35 to 45 applications required annually for BLSD control (55). All other banana diseases together account for only 3 to $5 \%$ of the total cost of disease control $(55,57)$.

The paucity of molecular studies of this devastating pathogen are linked, in part, to biological features of both host and pathogen that make the study of their interactions difficult and time consuming. Some of the challenges of the M. fijiensisbanana pathosystem include slow symptom development (which can take up to 2 months under optimal growth conditions), the generally slow growth rate of the fungus in vitro, the difficulty of reliably producing spore-based inoculum in vitro for pathogenicity assays, and the stringent environmental conditions required for successful infection and disease development, especially outside of the tropics.

Measurements of resistance of Musa spp. germplasm to M. fijiensis or effectiveness of fungicide applications for disease control are often carried out in field settings under conditions of natural

Corresponding author: A. C. L. Churchill; E-mail address: acc7@ cornell.edu

doi:10.1094/PHYTO-97-8-0916

(C) 2007 The American Phytopathological Society infestation (27,34-36,43,47,61). Alternatively, either ascospores or conidia may be used as the infective propagules for artificial inoculations in the field (62) or in greenhouse or growth-chamber settings $(5,20,24-26,37,38,46,59)$. Disease reactions observed with tissue-culture-derived banana plants artificially inoculated with Mycosphaerella banana pathogens generally are consistent with those found in field experiments with mature plants (2426,28,36-38,46).

Ascospores used for plant inoculations typically are obtained from necrotic banana leaves $(12,24,26,49,52)$. In vitro production of fruiting body structures (pseudothecia) and ascospores has been reported $(16,39)$ but has yet to become routine. In vitro production of conidia by $M$. fijiensis requires 10 to 14 days of growth under relatively stringent conditions (i.e., growth on a modified V8 medium at $20^{\circ} \mathrm{C}$ with continuous, cool-white fluorescent light) $(12,26,38)$. However, conidiation can be inconsistent within and across isolates and, in some cases, natural isolates are significantly impaired or deficient in conidia production in vitro. Furthermore, the temperature that stimulates optimal in vitro growth of the fungus, $\approx 28^{\circ} \mathrm{C}(25)$, generally is repressive to conidiation, which occurs optimally at $20^{\circ} \mathrm{C}$ (26) or lower (unpublished data).

Researchers have demonstrated the successful use of mycelia of $M$. fijiensis as inocula for in vitro-grown juvenile banana plants $(1,17,38,59)$, but detailed descriptions of the methods and data supporting the reproducibility and reliability of mycelium-based assays have never been reported. Alvarado Capó et al. (1) indicated that symptoms observed after inoculation with mycelia were similar to those recorded on plants in the field. Furthermore, six of seven cultivars evaluated responded to $M$. fijiensis mycelial inoculations in a manner similar to those seen under conditions of natural field infection. Twizeyimana et al. (59) reported that inoculation of in vitro plantlets with mycelial fragments caused significantly higher levels of disease severity and faster rates of disease progress compared with inoculations using conidial sus- 
pensions. However, they recommended conidial inoculum over mycelia due to the difficulty of quantifying and standardizing concentrations of mycelial fragments. Jones (28) used weighed mycelia of $M$. musicola, the causal agent of yellow Sigatoka, to evaluate young tissue-culture-derived plants of a variety of Musa genotypes for resistance to the fungus. In all cases where mycelium has been used as the infective propagules, host plants were young (1.5 to 4 months old after transplantation from tissue culture to soil) and disease response was recorded as a rating describing the stage of symptoms from which assessments of resistance, partial resistance, or susceptibility could be inferred.

Disease prevalence, severity, or intensity caused by Mycosphaerella pathogens of banana usually is reported using a scale that references a range of percentages of leaf area affected $(50,56,57)$. Carlier et al. (12) summarized F. Gauhl's modification of Stover's disease severity scoring system. With these methods, relative differences in resistance or susceptibility of Musa spp. to diseases caused by Mycosphaerella banana pathogens can be evaluated and reported on a scale of 0 (no symptoms) to 6 (>50\% of the leaf affected) using the stages of symptoms as described by Meredith and Lawrence (32) and Fouré et al. (18). For measuring the rate of disease development, records of changes in the average age of the "youngest leaf spotted" (YLS) between surveys are widely used $(50,56,60)$. Here, the number of the youngest leaf, counting down from the first unfurled leaf, showing mature spots of BLSD is recorded. Jacome and Schuh $(25,26)$ developed a diagrammatic scale based on a set of cards representing 10 degrees of disease severity ( 0.5 to $40 \%$ of leaf area covered with lesions) which then were used as standard reference points for disease assessment. From these analyses, they calculated a logistic equation for the rate of increase in "apparent infection rate", $r$, to quantify symptom development over time. Carlier et al. (13) summarized the current recommended technical guidelines for evaluating field resistance of bananas to Mycosphaerella leaf spots, including YLS, number of standing leaves (NSL), and index of nonspotted leaves (INSL).

Detached leaf assays, in which intact leaves-cut from the plant on a single edge-are maintained on filter paper or an agar medium throughout the virulence assay, have been used successfully in several systems $(4,6,9,22)$. Leaf disk assays for evaluating plant resistance or pathogen virulence, in which tissue is removed from a leaf, have been developed with success in other systems $(8,14,40)$. A banana leaf disk assay for BLSD has been reported $(15,31)$, but few details were provided and its use has not become routine. The challenges of maintaining excised banana leaf squares or young detached leaves in a nonsenescent state, comparable with that of leaves on intact plants, for up to several months to evaluate disease responses have limited the implementation of this method for routine use (58) (unpublished data). Twizeyimana et al. (59) recently described methods for maintaining excised leaf disks on agar medium supplemented with gibberellic acid to minimize leaf chlorosis during BLSD screening assays.

Outside of the tropics, additional challenges encountered with the $M$. fijiensis-Musa spp. pathosystem include the necessity to efficiently use tissue-culture-derived banana plants and relatively small environmental chambers for virulence assays. Controlled environment chambers are the only option for securely assessing the virulence of genetically modified or nonnative microorganisms, especially when reliable environmental conditions favorable to disease establishment cannot be achieved in other ways. The confined space available in such chambers limits the number of plants that can be inoculated concurrently and, thus, reduces the number of isolates that can be compared in a single experiment.

Experimental efficacy for the Mycosphaerella-banana pathosystem could be improved considerably by reducing inoculum production time, increasing the reliability of inoculum production, and increasing the number of isolates that can be evaluated in each experiment, especially when large numbers of mutant or natural isolates are to be screened for comparisons of virulence. Because rapidity of symptom appearance is correlated with the amount of inoculum infecting banana plants (51), it is critical to control this factor in all experiments in which conclusions will be made regarding pathogen virulence or plant susceptibility. We describe an effective method to assess the virulence of multiple $M$. fijiensis isolates on intact, susceptible banana plants held in an environmental growth chamber by application of weighed slurries of fragmented mycelia to the abaxial surface of leaves with a camel's hair brush. This method is quantitative but does not rely on the availability of conidia from the fungus as the source of inoculum. Furthermore, infections are limited to defined areas of large leaves, allowing one to test multiple isolates on a single leaf, as well as multiple leaves of a single plant or multiple plants, all within the confines of an environmental growth chamber capable of containing nonnative or genetically engineered isolates of Mycosphaerella banana pathogens.

\section{MATERIALS AND METHODS}

Organisms and culture conditions. $M$. fijiensis strains CIRAD743 and CIRAD301 were obtained from the Agricultural Research Centre for International Development (CIRAD, Montpellier, France). These strains previously were characterized as highly virulent on susceptible Grande Naine by Fullerton and Olsen (20) and identified in that original report as strains 298 (from Papua New Guinea) and 722 (from Nigeria), respectively. The mycelium and conidia of these wild-type strains are pigmented black due to melanization. M. fijiensis strains 743Pink and $301 \mathrm{~W} 2.2$ are spontaneous, pigmentation-impaired mutants isolated in our labs from CIRAD strains 743 and 301, respectively. Mutant strain 743Pink is pink in color and deficient in sporulation, whereas mutant strain $301 \mathrm{~W} 2.2$ produces creamcolored mycelium and sporulates abundantly. M. fijiensis strains routinely were cultured on plates of Dothistroma sporulation medium (DSM) $(2 \%$ [wt/vol] malt extract, $0.5 \%$ [wt/vol] yeast extract, and $1.5 \%$ [wt/vol] agar) or in liquid dothistromin medium (LDM) $(2.5 \%[\mathrm{wt} / \mathrm{vol}]$ malt extract and $2 \%$ [wt/vol] nutrient broth) (7).

Mycelial fragmentation for routine culture transfers and plant inoculations was carried out using a modified procedure of BalintKurti et al. (5). Screw-cap tubes (2-ml size) were preloaded with $0.45 \mathrm{~g}$ of 2.5-mm-diameter sterile glass beads (\#11079125; Biospec Products, Inc., Bartlesville, OK). Mycelium was scraped from plate cultures and transferred to bead-containing tubes, which were filled two-thirds full with sterile water and shaken for $10 \mathrm{~s}$ using a Mini-BeadBeater (Biospec Products, Inc.) set at $5,000 \mathrm{rpm}$. For routine culturing on agar plates, $100 \mu \mathrm{l}$ of fragmented mycelium was transferred to the surface of a DSM plate using wide-bore pipette tips and spread evenly across the plate with a sterile glass rod. Plates were incubated in the dark at $24^{\circ} \mathrm{C}$ for several days to 2 weeks. A lawn of growth formed during this time, the rate and density of which depended on the relative number of viable propagules present in the plated slurry.

Grande Naine (AAA) plantlets were obtained from Rahan Meristem (Kibbutz Rosh Hanikra, Western Galilee, Israel). They were propagated in vitro from plantlets cultured on RM medium under environmental conditions as described in Ganapathi et al. (21). Indole-3-acetic acid (IAA) was not included in the medium as a matter of routine because it tended to overstimulate root growth. After transfer to banana soil mix ( 1 bale of peat moss $\left[0.11 \mathrm{~m}^{3}\right], 1$ bag of medium or course vermiculite $\left[0.17 \mathrm{~m}^{3}\right], 1.5$ bags of perlite $\left[0.26 \mathrm{~m}^{3}\right], 90.72 \mathrm{~kg}$ of course-grade sand, $1.36 \mathrm{~kg}$ of lime, $0.59 \mathrm{~kg}$ of Peters Professional Uni-Mix Plus III [The Scotts Co., Marysville, $\mathrm{OH}$ ], and $1.81 \mathrm{~kg}$ of Osmocote Plus [15-912, N-P-K; The Scotts Co.]), plants were acclimatized in a shaded high-humidity tent in the greenhouse for at least 4 weeks, then moved to a greenhouse bench for further growth for an additional 
8 weeks. Plants used for inoculations were at least 1 to $1.5 \mathrm{~m}$ tall and 3 months old (i.e., after transfer from tissue culture to potting medium) but, more typically, 3 to 6 months old; leaves were at least $40 \mathrm{~cm}$ in length but frequently larger. Invariably, attempts were made to use plants of the same age within a single experiment.

Inoculum production and plant inoculations. Mycelia from actively growing LDM broth cultures grown at $25^{\circ} \mathrm{C}(<8$ days old) were fragmented by beadbeating (10 s, 5,000 rpm), and $500 \mu \mathrm{l}$ of slurry was spread as a thick layer onto each DSM plate overlaid with sterile cellophane. Open plates were incubated for 30 to $60 \mathrm{~min}$ in a laminar flow hood to remove excess water. Plates were closed, but not sealed, and incubated at $24^{\circ} \mathrm{C}$ in the dark for $48 \mathrm{~h}$. Mycelia were scraped off with a sterile spatula and fragmented again, as described below for each assay, in preweighed 2-ml tubes containing glass beads to determine mycelium weight.

Two sets of inoculations were conducted. The first set (two independent experiments named assays no. 1 and no. 2) involved the inoculation of plants with fragmented mycelium of four strains (743, 743Pink, 301, and 301W2.2). A master mycelium suspension was prepared for each strain that then was fragmented by beadbeating $(10 \mathrm{~s}, 5,000 \mathrm{rpm})$ and serially diluted to the final concentrations of mycelium at $60,12,2.4$, and $0.48 \mathrm{mg} / \mathrm{ml}$. The second set (two independent experiments named assays no. 3 and no. 4) involved the inoculation of plants with fragmented mycelium of a single strain, 743, at 12, 60, and $180 \mathrm{mg} / \mathrm{ml}$. For these assays, each target mycelium concentration was prepared individually and fragmented by applying four beadbeating intensities as described below in the colony forming unit (CFU) assessment. In all cases, mycelial dilutions were prepared in inoculation buffer (IB), which consisted of $2 \%$ LDM, $0.05 \%$ Tween 20 , and $0.05 \%$ Silwet L-77 (Loveland Industries Inc., Greeley, CO).

Inoculum was applied to 5-by-5-cm areas, delineated with a permanent marker, on the abaxial surfaces of the first and second fully unfolded banana leaves. All inoculations were carried out by randomly distributing the inoculation sites on target plants (using a fully randomized design) with three (assays no. 2, 3, and 4) or four replicates (assay no. 1) per experiment. Each mycelial suspension $(60 \mu \mathrm{l})$ was distributed across the delimited area using a camel's hair brush (VWR Scientific Products, West Chester, PA). Plants were allowed to dry for 30 to $60 \mathrm{~min}$ at room temperature and then transferred to a darkened dew room (Conviron, Pembina, ND) providing $100 \%$ humidity at $25^{\circ} \mathrm{C}$ for 3 days. Plants then were moved to a controlled environment chamber $(2.4 \mathrm{~m}$ width by $1.6 \mathrm{~m}$ depth by $2.4 \mathrm{~m}$ height; Conviron BDW40 Plant Growth Room) with a 14-h light: 10-h dark photoperiod, a light intensity of 400 to $600 \mu \mathrm{E} \cdot \mathrm{m}^{-2} \mathrm{~s}^{-1}$ measured $1 \mathrm{~m}$ above the floor of the chamber, continuous relative humidity of at least $95 \%$, and day and night temperatures of 27 and $25^{\circ} \mathrm{C}$, respectively, for up to 11 weeks. High-intensity, high-quality lighting in the growth chamber was supplied by 12 high-intensity discharge bulbs and 12 halogen bulbs.

CFU assessment. For assays no. 1 and 2, CFU concentration was assessed for each strain by sampling the beadbeaten $(10 \mathrm{~s}$, $5,000 \mathrm{rpm}$ ) $60-\mathrm{mg} / \mathrm{ml}$ master mycelium suspension, and plating serial dilutions as described below. For assays no. 3 and $4, \mathrm{CFU}$ concentration was assessed independently for each mycelium suspension and fragmentation treatment, and we obtained different CFU concentrations from each mycelium concentration by applying four beadbeating intensities. In assay no. 3, mycelium at each concentration determined by weight was beaten for $10 \mathrm{~s}$ without glass beads or for 1, 3, or $6 \mathrm{~s}$ with glass beads at 5,000 rpm. For assay no. 4 , beadbeating times were increased to achieve a wider range of CFU concentrations in the inocula than attained previously in assay no. 3. Mycelium at each concentration determined by weight either was vortexed in the presence of glass beads for $10 \mathrm{~s}$ or beadbeaten for 5,10 , or $15 \mathrm{~s}$ at $5,000 \mathrm{rpm}$.
For all assays, an aliquot of each master mycelium suspension was set aside in sterile conditions and serially diluted in IB. Typically, $50 \mu \mathrm{l}$ of the 1:50, 1:100, and 1:1000 dilutions in IB were spread as four replicates onto 6-cm-diameter petri dishes containing potato dextrose agar. Colony number was counted after 8 to 10 days of incubation at $24^{\circ} \mathrm{C}$ in the dark.

Disease rating. Plants were inspected weekly and symptom development was recorded at each inoculation site using a digital camera at a resolution of 640 by 480 pixels. Disease intensity was evaluated with the image analysis software Assess 1.0 (American Phytopathological Society, St. Paul, MN). For each image, the inoculated area was delimited manually. Recognition of diseased areas was achieved for each inoculation site by using either the hue or intensity plane (the latter in the case of very dark lesions) in the hue saturation intensity color space and manually adjusting the threshold levels until the diseased area was correctly recognized by the software. The proportion of the inoculated area that developed symptoms was recorded for each image. Proportions were arcsine square root transformed and used to calculate area under the disease progress curve (AUDPC) by trapezoidal integration of disease severity over time for each treatment replicate (10).

Statistical analyses. Dose-response relationship models for each of the strains were estimated using the general linear model (GLM) module of SPSS 13.0 (SPSS Inc., Chicago). The dose of the fragmented mycelia was expressed either as $\mathrm{mg} / \mathrm{ml}$ (MYC) or $\mathrm{CFU} / \mathrm{ml}$ (CFU), while the responses were expressed as AUDPC. Both inoculum dose and AUDPC were log transformed to linearize models and equalize variances, whereas the categorical variables (strain, plant, and fragmentation treatment) were recoded as dummy variables. The models used for assays no. 1 and 2 were

$$
\log (\mathrm{AUDPC})=\beta_{0}+\beta_{1} \log (\mathrm{MYC})+\delta_{0 \mathrm{i}} \mathrm{ST}_{\mathrm{i}}+\delta_{1 \mathrm{i}} \mathrm{ST}_{\mathrm{i}} \log (\mathrm{MYC})+\varepsilon
$$

$$
\log (\mathrm{AUDPC})=\beta_{0}+\beta_{1} \log (\mathrm{CFU})+\delta_{0 \mathrm{i}} \mathrm{ST}_{\mathrm{i}}+\delta_{1 \mathrm{i}} \mathrm{ST}_{\mathrm{i}} \log (\mathrm{CFU})+\varepsilon
$$

where $\beta_{0}$ is the intercept of the reference strain, $\beta_{1}$ is the effect of either MYC or CFU of the reference strain, $\delta_{0 \mathrm{i}}$ is the differential intercept of strain $i\left(\mathrm{ST}_{\mathrm{i}}\right), \delta_{1 \mathrm{i}}$ is the differential slope of $\mathrm{ST}_{\mathrm{i}}$, and $\varepsilon$ is the variability not accounted for by the model. The coefficients $\delta_{0}$ and $\delta_{1}$ represent a measure of the relative virulence levels of a particular strain compared with a reference strain. Comparison among strains was achieved by using each one as the reference in successive fittings of the model. Tests of equality of slopes and intercepts between estimated dose-response relationships (i.e., statistical significance of the coefficients $\delta_{0 \mathrm{i}}$ and $\delta_{1 \mathrm{i}}$ ) were applied to evaluate differences in virulence among strains.

Effects of mycelium amounts and fragmentation treatments on CFU levels were evaluated in the second set of inoculations (assays no. 3 and 4 ) with the following equation:

$$
\log (\mathrm{CFU})=\beta_{0}+\beta_{1} \log (\mathrm{MYC})+\delta_{1 \mathrm{i}} \mathrm{FR}_{\mathrm{i}}+\varepsilon
$$

where $\beta_{0}$ is the intercept estimated for the fragmentation treatment used as the reference, $\beta_{1}$ is the effect of MYC, $\delta_{1 \mathrm{i}}$ is the differential effect of $\mathrm{FR}_{\mathrm{i}}$ (fragmentation treatment $i$ ), and $\varepsilon$ is the variability not accounted for by the model.

Dose-response, using MYC as the inoculum, was modeled for assays no. 3 and 4 using the following equation:

$$
\begin{aligned}
\log (\mathrm{AUDPC})= & \beta_{0}+\beta_{1} \log (\mathrm{MYC})+\delta_{1 \mathrm{i}} \mathrm{PL}_{\mathrm{i}}+\delta_{2 \mathrm{i}} \mathrm{FR}_{\mathrm{i}}+ \\
& \delta_{3 \mathrm{i}} \mathrm{FR}_{\mathrm{i}} \log (\mathrm{MYC})+\varepsilon
\end{aligned}
$$

where $\beta_{0}$ is the intercept calculated for the plant and fragmentation treatment used as the references, $\beta_{1}$ is the effect of MYC, $\delta_{1 \mathrm{i}}$ is the differential intercept of $\mathrm{PL}_{\mathrm{i}}$ (plant $i$ ), $\delta_{2 \mathrm{i}}$ is the differential intercept of $\mathrm{FR}_{\mathrm{i}}$ (fragmentation treatment $i$ ), $\delta_{3 \mathrm{i}}$ is the differential 
slope of $\mathrm{FR}_{\mathrm{i}}$, and $\varepsilon$ is the variability not accounted for by the model.

Dose-response for assays no. 3 and 4 also was modeled using $\mathrm{CFU}$ as inoculum with the following equation:

$$
\log (\mathrm{AUDPC})=\beta_{0}+\beta_{1} \log (\mathrm{CFU})+\delta_{1 \mathrm{i}} \mathrm{PL}_{\mathrm{i}}+\varepsilon
$$

where $\beta_{0}$ is the intercept calculated for the reference plant, $\beta_{1}$ is the effect of CFU, $\delta_{1 \mathrm{i}}$ is the differential intercept of $\mathrm{PL}_{\mathrm{i}}$ (plant $i$ ), and $\varepsilon$ is the variability not accounted for by the model.

The effect of CFU level for a given mycelium concentration on AUDPC scores from virulence assays no. 3 and 4 was examined using the following equation:

$$
\log \left(\mathrm{AUDPC}_{\mathrm{m}}\right)=\beta_{0}+\beta_{1} \log \left(\mathrm{CFU}_{\mathrm{m}}\right)+\varepsilon
$$

where $\mathrm{AUDPC}_{\mathrm{m}}$ is the AUDPC score for a given mycelium concentration, $\beta_{0}$ is the intercept, $\beta_{1}$ is the effect of $\mathrm{CFU}$, and $\varepsilon$ is the variability not accounted for by the model.

\section{RESULTS}

Comparison of virulence of strains using fragmented mycelia as inocula. We tested the ability of fragmented mycelia to cause disease on Grande Naine banana plants, which are highly susceptible to $M$. fijiensis, using four strains and four concentrations of fragmented mycelia in two independent virulence assays (assays no. 1 and 2). Both assays resulted in the development of necrotic tissue localized to each inoculation area (Fig. 1A and B; data not shown). The first macroscopic symptoms for strains 743, 301 , and $301 \mathrm{~W} 2.2$ became visible 25 days after inoculation (DAI) in assay no. 1 and 35 DAI in assay no. 2 (Fig. 2). In both assays, they appeared as light, localized discolorations that later darkened and enlarged, assuming the typical pattern of BLSD lesions (11). Symptoms caused by strain 743 progressed more quickly than those caused by 301 and 301W2.2 (Figs. 1A and 2). By the end of each assay (62 and 77 DAI for assays no. 1 and 2, respectively), the lesions caused by 743 were the most extensive (Fig. 1A), resulting in necrosis that covered, on average, $90 \%$ or more of each inoculated area in inoculations with mycelium at $60 \mathrm{mg} / \mathrm{ml}$ (Fig. 2). Plants inoculated with strain 743Pink showed early development (as early as $14 \mathrm{DAI}$ ) of small reddish specks that enlarged in size only slightly thereafter. Strain 743Pink never developed typical BLSD lesions in either assay (Figs. 1A and 2) or in numerous other plant inoculation trials with this strain (data not shown).

The relationship between inoculum levels using weighed mycelium (i.e., MYC or mycelium at $\mathrm{mg} / \mathrm{ml}$ ) and disease severity for the four strains was modeled using equation 1. For both assays no. 1 and 2, the models were statistically significant with an adjusted $R^{2}$ of 0.897 and 0.947 , respectively (Table 1 ). The effects of strain, MYC, and the interaction term MYC $\times$ strain were significant in both assays, indicating that both isolate and mycelium amount had substantial impact on the final disease severity scores. Dose-response lines estimated for assays no. 1 and 2 using equation 1 are shown in Figure $3 \mathrm{~A}$ and $\mathrm{B}$, respectively, and the corresponding equation coefficients are reported in Table 2. In assay no. 1, strain 743 differed significantly in the value of the intercept $\left(\beta_{0}=0.560\right)$ from $301\left(\beta_{0}=0.274\right)$, 743Pink $\left(\beta_{0}=\right.$ $-0.439)$, and 301W2.2 $\left(\beta_{0}=-0.346\right)$. Intercepts of the pairs 301/743Pink and 301/301W2.2 also were significantly different, whereas the difference was not significant in the case of 743Pink/ 301W2.2. Based solely on the values of the intercepts, relative virulence levels could be summarized as $743>301>301 \mathrm{~W} 2.2=$ 743Pink. However, although 743, 301, and 743Pink did not differ significantly in their slope coefficients $\left(\beta_{1}=0.488,0.475\right.$, and 0.428 , respectively), strain $301 \mathrm{~W} 2.2$ had a significantly larger dose-response slope $\left(\beta_{1}=0.773\right)$ compared with the other three strains (Table 2). This means that, at the lowest inoculum concentration, 301W2.2 behaved similarly to 743Pink; whereas, at the highest inoculum concentration, it was not significantly different from 301 (Fig. 3A). We conclude that, for assay no. 1, using weighed, fragmented mycelium as the measure for inoculum concentration, the virulence ranking was $743>301 \geq 301 \mathrm{~W} 2.2>$ 743Pink.

Dose-response relationships for strains 743, 301, 301W2.2, and 743Pink were reestimated by fitting data from a second independent experiment (assay no. 2). In this second assay, the strain 743 intercept $\left(\beta_{0}=0.369\right)$ again was significantly larger than the intercepts of the other three strains. Strain 743Pink was at the other end of the spectrum, with an intercept value $\left(\beta_{0}=-0.137\right)$ significantly smaller than the other strains. The 301W2.2 and 301 intercepts ( $\beta_{0}=0.100$ and 0.060 , respectively) did not differ significantly. Strain 743 also had a significantly larger value of the slope $\left(\beta_{1}=0.676\right)$ compared with $301\left(\beta_{1}=0.544\right)$, which was not significantly different from 301W2.2 $\left(\beta_{1}=0.591\right)$. The slope value for strain 743Pink $\left(\beta_{1}=0.159\right)$ was significantly smaller than those of the other strains. Based on this analysis using weighed, fragmented mycelia to determine inoculum concentration, relative virulence levels for assay no. 2 were summarized as $743>301=301 \mathrm{~W} 2.2>743$ Pink. These results were comparable with those of assay no. 1, with the exception that, in assay no. 2, virulence levels were equivalent for 301 and $301 \mathrm{~W} 2.2$ at all mycelium concentrations tested. For both assays, significant differences between strains were detected less reliably at the lower concentrations of inocula assayed $(12,2.4$, and $0.48 \mathrm{mg} / \mathrm{ml})$ (Fig. 3; Table 2; data not shown).

Using CFU as a measurement of inoculum concentration. For assays no. 1 and 2, the CFU counts showed that the fragmentation process supported high viability but, also, that there were surprisingly high levels of variability in CFU densities, both between strains and between experiments with the same strain (Table 3). There also was a trend, especially evident in assay no. 2 , suggesting that mycelia of strains deficient in black or brown pigmentation, such as 301W2.2 and 743Pink, were fragmented by beadbeating more efficiently than were the wild-type strains 301 and 743 .

The high variability of CFU counts between isolates raised the question of whether using this measure to quantify inoculum had any effect on disease severity, i.e., which is the preferable measure of inoculum concentration-weighed, fragmented mycelia or CFU of fragmented mycelia? The problem first was addressed by rerunning the GLM analysis for assays no. 1 and 2 using CFU as the measure of inoculum concentration, instead of MYC, to see whether this analysis would lead to a different interpretation of the data. AUDPC scores from assays no. 1 and 2 were fit using equation 2 . We did not expect differences in the values of the slopes because, for both this and previous analyses, inocula for each strain were generated as a fivefold serial dilution of the highest dosage. However, a change in the value of the intercepts and a possible shift of the regression lines was expected. Models obtained using CFU concentration as an independent variable (Fig. 3C and 3D for assays no. 1 and 2, respectively) were significant and had $R^{2}$ values that were the same as the models obtained using MYC as an independent variable (Table 1). For assay no. 1 , strain 743 had the largest intercept $\left(\beta_{0}=-1.388\right)$ followed by strain $301\left(\beta_{0}=-1.761\right), 743$ Pink $\left(\beta_{0}=-2.417\right)$ and $301 \mathrm{~W} 2.2\left(\beta_{0}=-3.318\right)$ (Table 2). Differences in the intercepts for the pairs 743/301W2.2, 301W2.2/301, and 743Pink/743 were significant, whereas no significant differences were found for the pairs 301/743, 301/743Pink, and 743Pink/301W2.2.

Strain 301W2.2 had the largest $\beta_{1}$ coefficient $\left(\beta_{1}=0.773\right)$ followed by $743\left(\beta_{1}=0.488\right), 301\left(\beta_{1}=0.475\right)$, and 743Pink $\left(\beta_{1}=\right.$ 0.428 ). Differences between the slopes of $301 \mathrm{~W} 2.2$ and the other three strains were significant whereas differences in the values of the slopes for the pairs 743/301, 743/743Pink, and 301/743Pink 
were not because of the relatively high value of the standard error in the estimate of the regression parameter (data not shown). Because of the lack of statistical difference in both $\beta_{0}$ and $\beta_{1}$ coefficients, the virulence of strain 301 could not be considered different from either 743 or 743Pink. On the other hand, 743 was determined to be more virulent than 743Pink because it had a larger intercept value. Although $301 \mathrm{~W} 2.2$ had the largest $\beta_{1}$ coefficient, it also had the smallest intercept and, within the range of CFU tested, its virulence could be considered intermediate between 743 and 743Pink and no different from 301 (Fig. 3C). This analysis did not return a clear virulence ranking but can be summarized as follows. Using CFU for determining inoculum concentration, the virulence ranking in assay no. 1 was $743>$ $301 \mathrm{~W} 2.2>$ 743Pink, whereas the virulence level of strain 301 could not be clearly distinguished from any of the other three strains due to the high variability in the data.

For assay no. 2, strains 743, 301, and 301W2.2 had very similar intercept values $\left(\beta_{0}=-2.467,-2.500\right.$ and -2.464 , respectively)
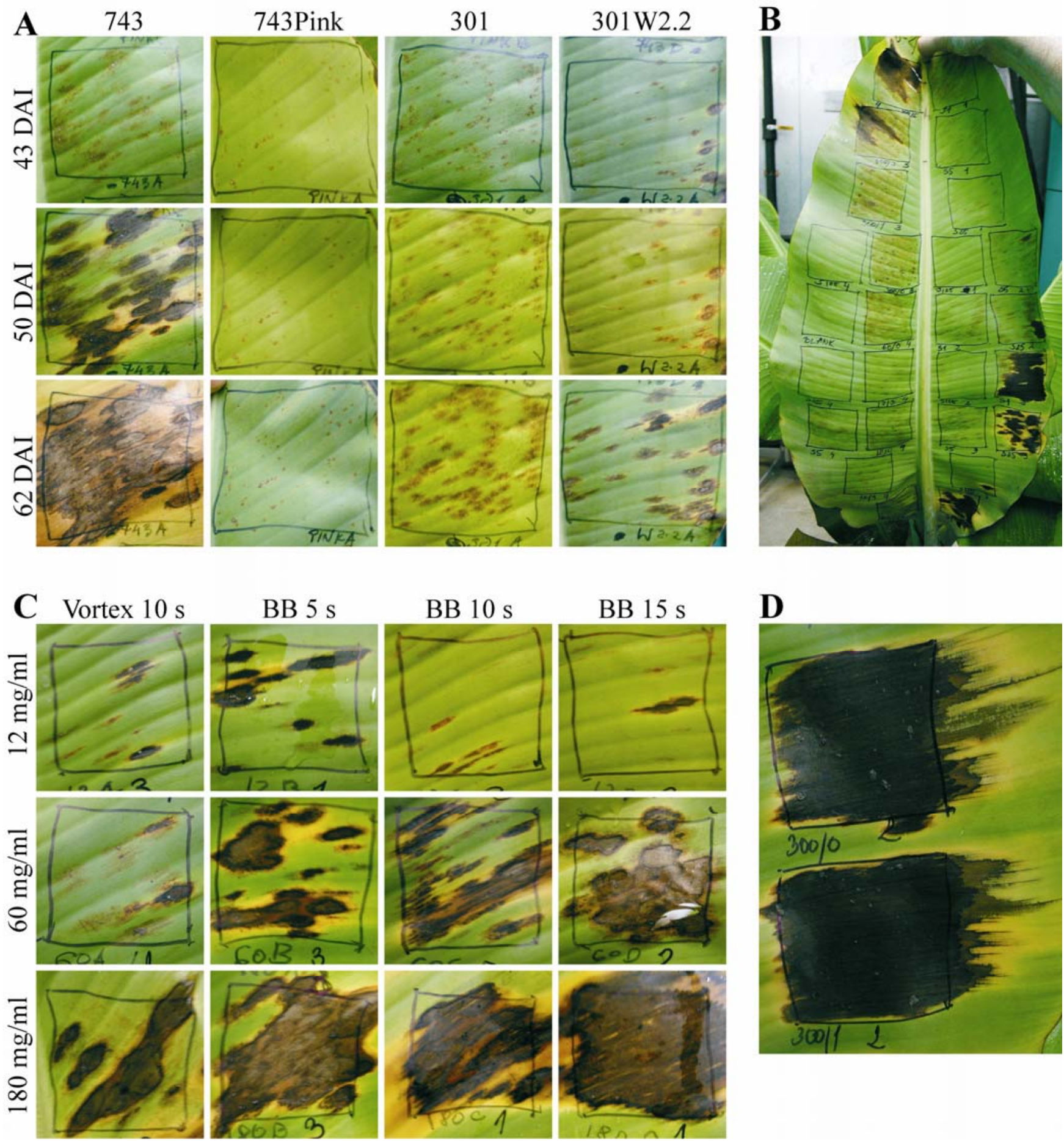

D

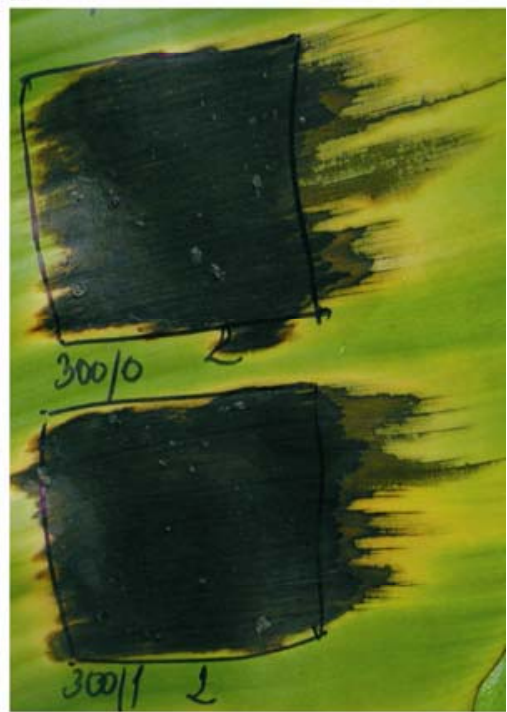

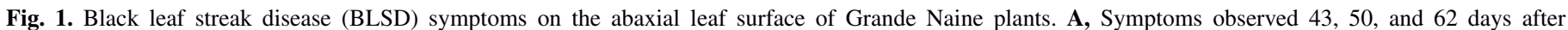

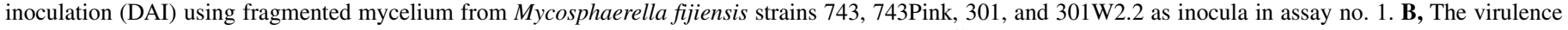

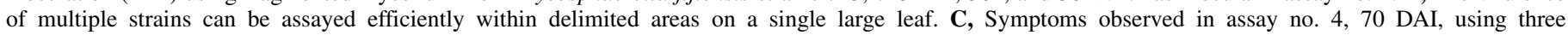

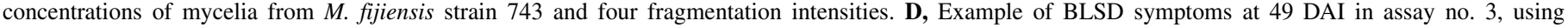

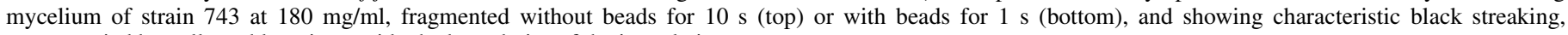
accompanied by yellow chlorosis, outside the boundaries of the inoculation area. 
that did not differ significantly from each other. For strain 743Pink, this coefficient was significantly larger $\left(\beta_{0}=-0.855\right)$. Strain 743 had the largest $\beta_{1}$ coefficient $\left(\beta_{1}=0.676\right)$ followed by $301 \mathrm{~W} 2.2$ $\left(\beta_{1}=0.591\right), 301\left(\beta_{1}=0.544\right)$, and 743Pink $\left(\beta_{1}=0.159\right)$. Differences in the values of these coefficients were significant for the pairs 743/301, 743/743Pink, 301/743Pink, and 301W2.2/743Pink but not significant for the other strain combinations. Although 743Pink had the largest intercept value, its very low value for the slope suggested that it was the least virulent strain within the concentrations of CFUs tested in the assay (Fig. 3D). Because of its significantly larger $\beta_{1}$ value, 743 was the most virulent strain, whereas 301 and $301 \mathrm{~W} 2.2$ had comparable virulence levels because both $\beta_{0}$ and $\beta_{1}$ coefficients were not statistically different. In summary, for assay no. 2 , the virulence ranking using CFU was $743>301=301 \mathrm{~W} 2.2>743$ Pink, which was equivalent to the ranking given for the same assay using MYC as the measure of inoculum dose.
Assessment of CFU effect. To determine whether the level of mycelium fragmentation had any effect on disease severity, we compared the AUDPC obtained with three concentrations of fragmented mycelia $(12,60$, and $180 \mathrm{mg} / \mathrm{ml})$ of a single strain of M. fijiensis, 743, each one subjected to four different fragmentation intensities (Figs. 1C and 4; Table 4). Hence, for each inoculum concentration measured as mycelial weight, we varied the amount of CFU. The experiments were referred to as assays no. 3 and 4 . The range of CFU produced for each mycelium concentration differed greatly in the two assays. In assay no. 3, the difference between the highest and lowest CFU value (regardless of the concentration in terms of mycelium weight) was only 6fold whereas, in assay no. 4, the difference was 34-fold (Table 4).

Analyses based on equation 3 indicated that the two assays differed in the ability of the fragmentation process to explain $\mathrm{CFU}$ variability. In assay no. 3, CFU levels were dependent mainly on MYC, and fragmentation was a significant explanatory variable
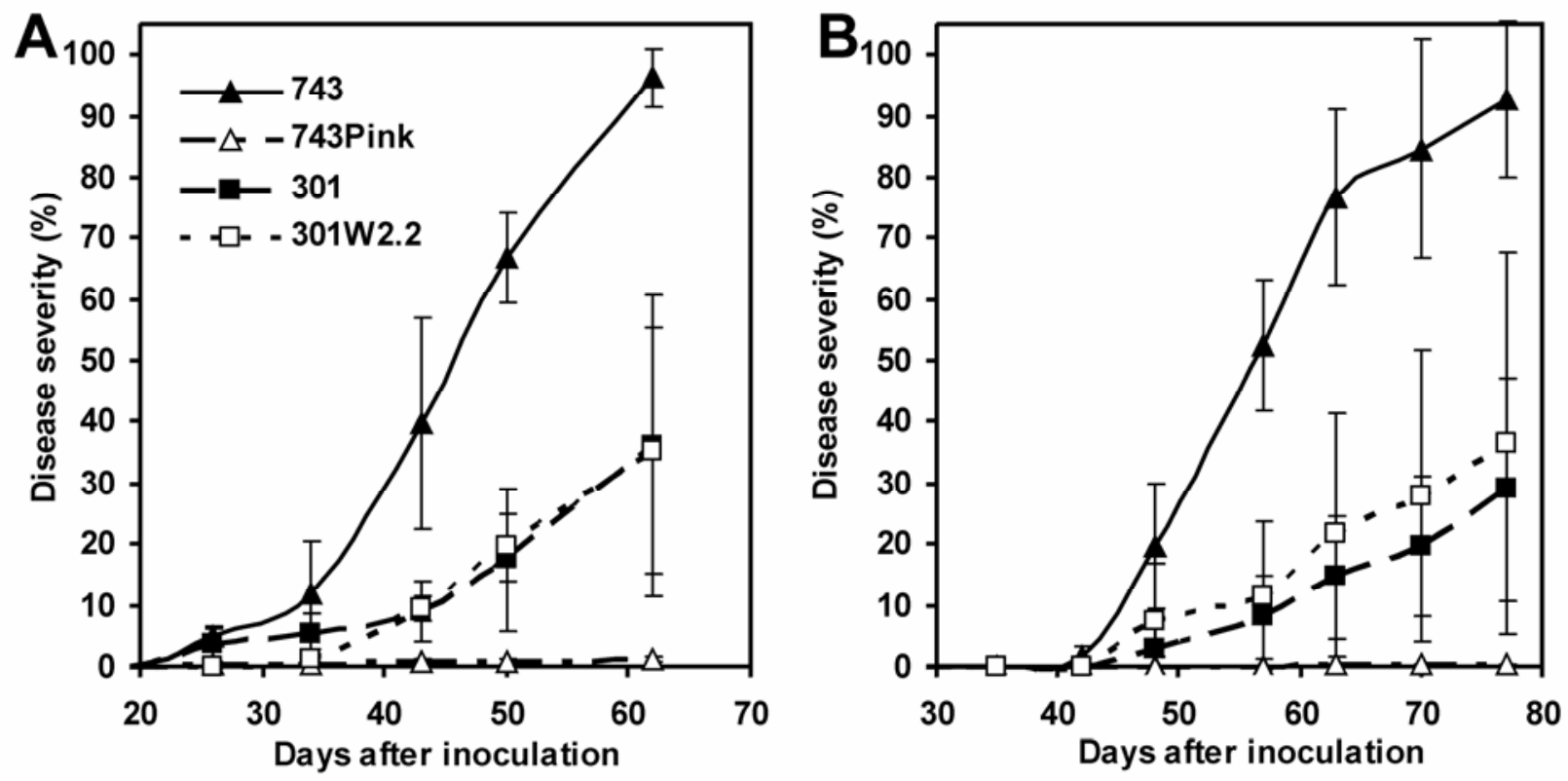

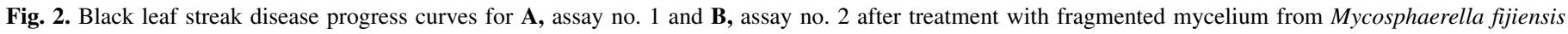
strains 743, 743Pink, 301, and 301W2.2 at $60 \mathrm{mg} / \mathrm{ml}$. Bars represent standard deviations.

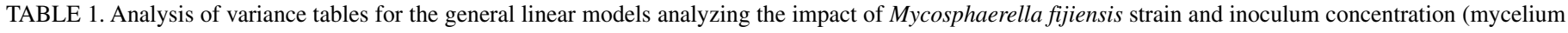
in $\mathrm{mg} / \mathrm{ml}[\mathrm{MYC}]$ ) or $\mathrm{CFU} / \mathrm{ml}[\mathrm{CFU}]$ ) on area under the disease progress curve scores

\begin{tabular}{|c|c|c|c|c|c|c|c|c|}
\hline \multirow[b]{2}{*}{ Source $^{\mathrm{a}}$} & \multicolumn{4}{|c|}{ Assay no. 1} & \multicolumn{4}{|c|}{ Assay no. 2} \\
\hline & Sum of squares & $\mathrm{df}$ & $F$ & $P$ & Sum of squares & df & $F$ & $P$ \\
\hline \multicolumn{9}{|l|}{ MYC as variable } \\
\hline Corrected model & $22.171^{b}$ & 7 & 79.406 & 0.000 & $13.047^{\mathrm{c}}$ & 7 & 120.808 & 0.000 \\
\hline Intercept & 0.005 & 1 & 0.126 & 0.724 & 0.247 & 1 & 15.993 & 0.000 \\
\hline MYC & 11.435 & 1 & 286.673 & 0.000 & 7.107 & 1 & 460.687 & 0.000 \\
\hline Strain & 5.994 & 3 & 50.093 & 0.000 & 0.835 & 3 & 18.031 & 0.000 \\
\hline MYC $\times$ strain & 0.721 & 3 & 6.027 & 0.001 & 1.155 & 3 & 24.949 & 0.000 \\
\hline Error & 2.234 & 56 & $\ldots$ & $\ldots$ & 0.617 & 40 & $\ldots$ & $\ldots$ \\
\hline Total & 34.998 & 64 & $\ldots$ & $\ldots$ & 23.706 & 48 & $\ldots$ & $\ldots$ \\
\hline \multicolumn{9}{|l|}{$\mathrm{CFU}$ as variable } \\
\hline Corrected model & $22.172^{\mathrm{d}}$ & 7 & 79.410 & 0.000 & $13.047^{\mathrm{e}}$ & 7 & 120.807 & 0.000 \\
\hline Intercept & 7.754 & 1 & 194.392 & 0.000 & 4.592 & 1 & 297.670 & 0.000 \\
\hline CFU & 11.435 & 1 & 286.690 & 0.000 & 7.107 & 1 & 460.681 & 0.000 \\
\hline Strain & 0.935 & 3 & 7.812 & 0.000 & 0.518 & 3 & 11.192 & 0.000 \\
\hline CFU $\times$ strain & 0.721 & 3 & 6.028 & 0.001 & 1.155 & 3 & 24.949 & 0.000 \\
\hline Error & 2.234 & 56 & $\ldots$ & $\ldots$ & 0.617 & 40 & $\ldots$ & $\ldots$ \\
\hline Total & 34.998 & 64 & $\ldots$ & $\ldots$ & 23.706 & 48 & $\ldots$ & $\ldots$ \\
\hline
\end{tabular}

a MYC and CFU used as independent variables.

${ }^{\mathrm{b}} R^{2}=0.908$; adjusted $R^{2}=0.897$.

${ }^{\mathrm{c}} R^{2}=0.955$; adjusted $R^{2}=0.947$.

${ }^{\mathrm{d}} R^{2}=0.908 ;$ adjusted $R^{2}=0.897$.

e $R^{2}=0.955$; adjusted $R^{2}=0.947$. 

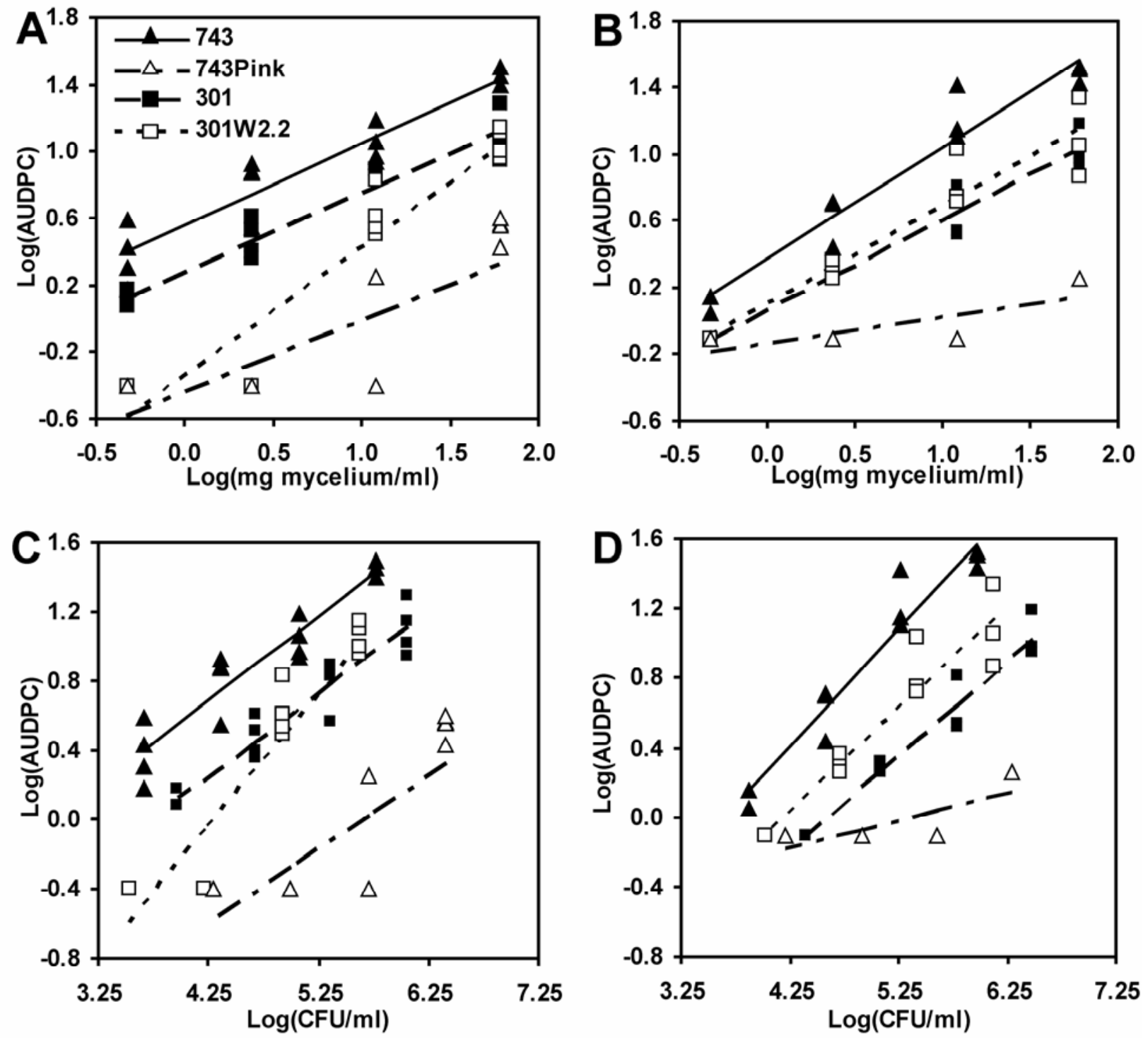

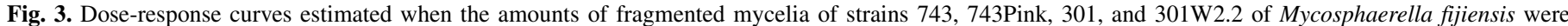

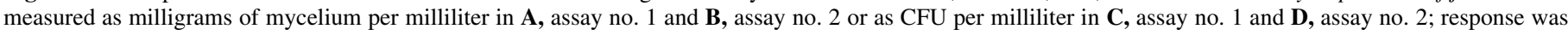
expressed as the $\log$ of the area under the disease progress curve $[\log ($ AUDPC) $]$.

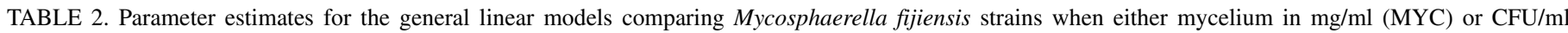
(CFU) is used as the independent variable in assays no. 1 and 2

\begin{tabular}{|c|c|c|c|c|c|c|c|c|c|c|c|}
\hline \multirow[b]{2}{*}{ Ref. strain ${ }^{a}$} & \multirow[b]{2}{*}{ Assay no. } & \multicolumn{2}{|c|}{ Reference strain effects ${ }^{\mathrm{b}}$} & \multicolumn{4}{|c|}{ Differential strain effects $\left(\delta_{0}\right)^{\mathrm{b}}$} & \multicolumn{4}{|c|}{ Differential inoculum effects $\left(\delta_{1}\right)^{\mathrm{b}}$} \\
\hline & & Main $\left(\beta_{0}\right)$ & Inoculum $\left(\beta_{1}\right)$ & 301 & $301 \mathrm{~W} 2.2$ & 743 & 743Pink & 301 & $301 \mathrm{~W} 2.2$ & 743 & 743Pink \\
\hline \multicolumn{12}{|l|}{$\overline{\mathrm{MYC}}$} \\
\hline \multirow[t]{2}{*}{301} & 1 & 0.274 & 0.475 & $\ldots$ & -0.620 & 0.286 & -0.713 & $\ldots$ & 0.298 & $0.013^{\mathrm{ns}}$ & $-0.047^{\mathrm{ns}}$ \\
\hline & 2 & $0.060^{\mathrm{ns}}$ & 0.544 & $\ldots$ & $0.040^{\mathrm{ns}}$ & 0.309 & -0.197 & $\ldots$ & $0.047^{\mathrm{ns}}$ & 0.132 & -0.385 \\
\hline \multirow[t]{2}{*}{$301 \mathrm{~W} 2.2$} & 1 & -0.346 & 0.773 & 0.620 & $\ldots$ & 0.907 & $-0.093^{\mathrm{ns}}$ & -0.298 & $\ldots$ & -0.285 & -0.345 \\
\hline & 2 & 0.100 & 0.591 & $-0.040^{\mathrm{ns}}$ & $\ldots$ & 0.269 & -0.237 & $-0.047^{\mathrm{ns}}$ & $\ldots$ & $0.086^{\mathrm{ns}}$ & -0.432 \\
\hline \multirow[t]{2}{*}{743} & 1 & 0.560 & 0.488 & -0.286 & -0.907 & $\ldots$ & -1.000 & $-0.013^{\mathrm{ns}}$ & 0.285 & $\ldots$ & $-0.060^{\mathrm{ns}}$ \\
\hline & 2 & 0.369 & 0.676 & -0.309 & -0.269 & $\ldots$ & -0.506 & -0.132 & $-0.086^{\mathrm{ns}}$ & $\ldots$ & -0.518 \\
\hline \multirow[t]{2}{*}{ 743Pink } & 1 & -0.439 & 0.428 & 0.713 & $0.093^{\mathrm{ns}}$ & 1.000 & $\ldots$ & $0.047^{\mathrm{ns}}$ & 0.345 & $0.060^{\mathrm{ns}}$ & $\ldots$ \\
\hline & 2 & -0.137 & 0.159 & 0.197 & 0.237 & 0.506 & $\ldots$ & 0.385 & 0.432 & 0.518 & $\ldots$ \\
\hline \multicolumn{12}{|l|}{$\mathrm{CFU}$} \\
\hline \multirow[t]{2}{*}{301} & 1 & -1.761 & 0.475 & $\ldots$ & -1.557 & $0.373^{\text {ns }}$ & $-0.656^{\mathrm{ns}}$ & $\ldots$ & 0.298 & $0.013^{\mathrm{ns}}$ & $-0.047^{\mathrm{ns}}$ \\
\hline & 2 & -2.500 & 0.544 & $\ldots$ & $0.036^{\mathrm{ns}}$ & $0.033^{\mathrm{ns}}$ & 1.645 & $\ldots$ & $0.047^{\mathrm{ns}}$ & 0.132 & -0.385 \\
\hline \multirow[t]{2}{*}{$301 \mathrm{~W} 2.2$} & 1 & -3.318 & 0.773 & 1.557 & $\ldots$ & 1.931 & $0.902^{\text {ns }}$ & -0.298 & $\ldots$ & -0.285 & -0.345 \\
\hline & 2 & -2.464 & 0.591 & $-0.036^{\mathrm{ns}}$ & $\ldots$ & $-0.003^{\mathrm{ns}}$ & 1.609 & $-0.047^{\mathrm{ns}}$ & $\ldots$ & $0.086^{\mathrm{ns}}$ & -0.432 \\
\hline \multirow[t]{2}{*}{743} & 1 & -1.388 & 0.488 & $-0.373^{\mathrm{ns}}$ & -1.931 & $\ldots$ & -1.029 & $-0.013^{\mathrm{ns}}$ & 0.285 & $\ldots$ & $-0.060^{\mathrm{ns}}$ \\
\hline & 2 & -2.467 & 0.676 & $-0.033^{\mathrm{ns}}$ & $0.003^{\mathrm{ns}}$ & $\ldots$ & 1.613 & -0.132 & $-0.086^{\mathrm{ns}}$ & $\ldots$ & -0.518 \\
\hline \multirow[t]{2}{*}{ 743Pink } & 1 & -2.417 & 0.428 & $0.656^{\mathrm{ns}}$ & $-0.902^{\mathrm{ns}}$ & 1.029 & $\ldots$ & $0.047^{\mathrm{ns}}$ & 0.345 & $0.060^{\mathrm{ns}}$ & $\ldots$ \\
\hline & 2 & -0.855 & 0.159 & -1.645 & -1.609 & -1.613 & $\ldots$ & 0.385 & 0.432 & 0.518 & $\ldots$ \\
\hline
\end{tabular}

${ }^{a} \mathrm{MYC}$ and $\mathrm{CFU}$ used as independent variables.

b All terms are significant at $P<0.05$ unless marked with ns (not significant). 
only when modeled together with MYC (Table 5). In assay no. 4, fragmentation levels alone were able to explain 94\% of CFU variability (Table 5), and MYC was not significant whether it was used as a continuous or a categorical variable (data not shown). This result gave us the opportunity to evaluate whether very different outcomes of the fragmentation process significantly altered AUDPC.

Data from plant inoculations were analyzed using equations 4 and 5 (Table 6). These equations contained "plant" as a factor even though inoculations were carried out using a fully ran-

TABLE 3. CFU counts (average) of fragmented Mycosphaerella fijiensis mycelium at a concentration of $60 \mathrm{mg} / \mathrm{ml}$

\begin{tabular}{lrrrrr}
\hline & \multicolumn{2}{c}{ Assay no. 1 } & & \multicolumn{2}{c}{ Assay no. 2 } \\
\cline { 2 - 3 } \cline { 5 - 6 } Isolate & \multicolumn{1}{c}{$\mathrm{CFU} / \mathrm{ml}$} & \multicolumn{1}{c}{$\mathrm{SD}^{\mathrm{a}}$} & & $\mathrm{CFU} / \mathrm{ml}$ & \multicolumn{1}{c}{$\mathrm{SD}^{\mathrm{a}}$} \\
\hline 301 & $1,157,063$ & 177,726 & & $1,314,394$ & 92,681 \\
$301 \mathrm{~W} 2.2$ & 419,375 & 95,886 & & $3,041,667$ & 232,145 \\
743 & 589,875 & 49,155 & & 937,500 & 74,066 \\
743Pink & $2,505,938$ & 506,749 & & $2,009,470$ & 100,003 \\
\hline
\end{tabular}

${ }^{\mathrm{a}} \mathrm{SD}=$ standard deviation.
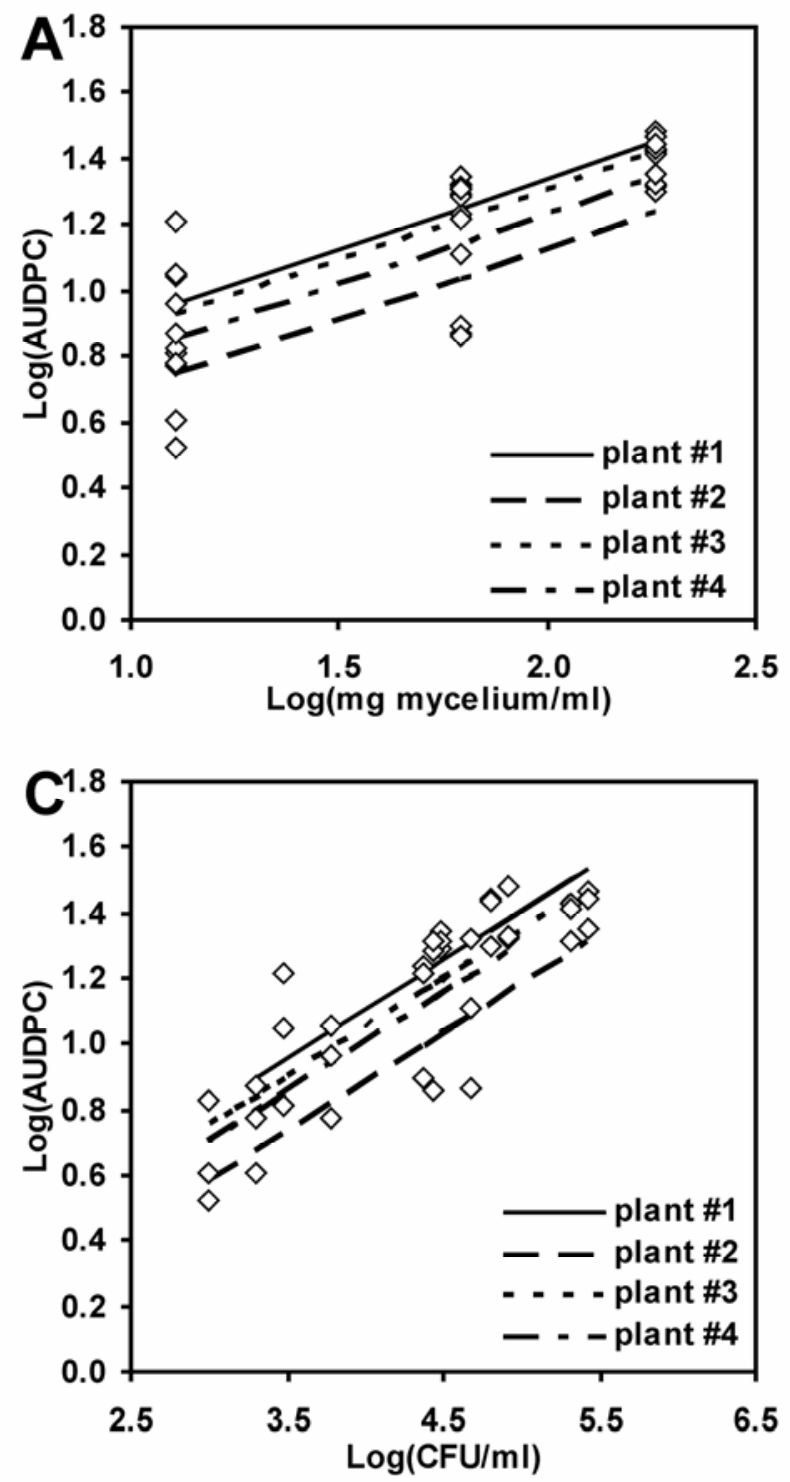

domized design. During the data analysis stage, we observed unanticipated variability in the plant response. Therefore, we chose to include the plant among the independent variables even though the distribution of the replicates among them was unbalanced.

For assay no. 3, both models were significant and had similar explanatory abilities as indicated by their adjusted $R^{2}$ values of 0.73 . When data were analyzed with equation 4 , the only significant explanatory variable was MYC whereas, in the case of equation 5, both CFU and plant (although marginally) were significant. This analysis indicated that, for assay no. 3, both MYC and CFU had similar predictive abilities. The same analyses were repeated for assay no. 4 . The fitting of equation 4 was significant, and the model had good explanatory ability (adjusted $R^{2}=0.87$ ). Unlike assay no. 3, all factors included in equation 4 were significant although MYC had, by far, the highest explanatory ability (Tables 6 and 7). Subsequent modeling of AUDPC scores from assay no. 4, using $\mathrm{CFU}$ and plant as the independent variables (equation 5), was significant but with negligible explanatory ability (adjusted $R^{2}=0.22$ ). Plant was not a significant variable and, unlike in assay no. 3, CFU accounted for a very small fraction of AUDPC variability (Tables 6 and 7).
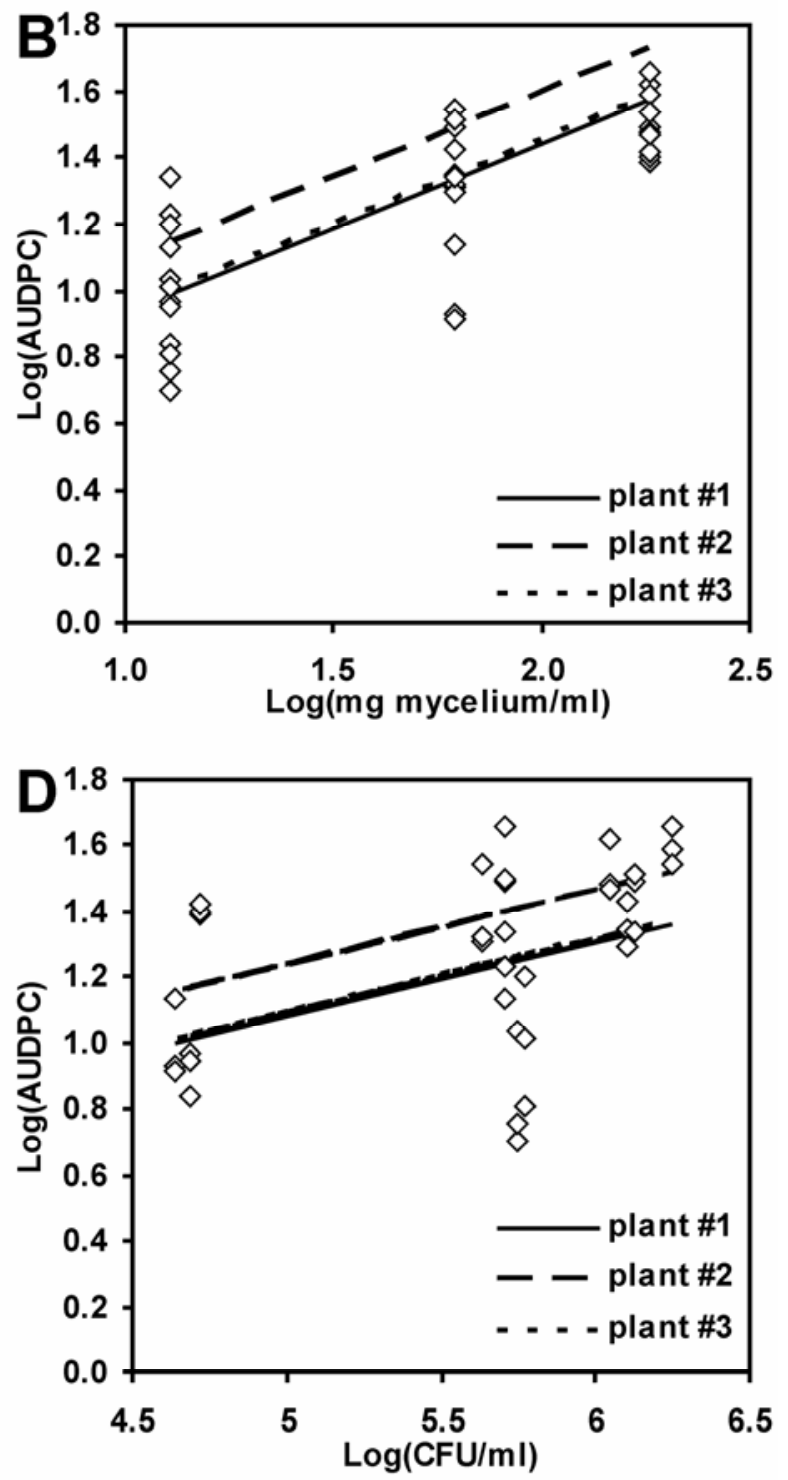

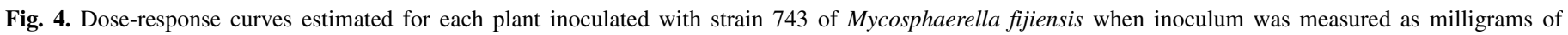

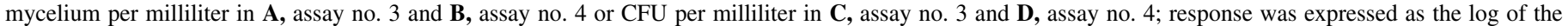

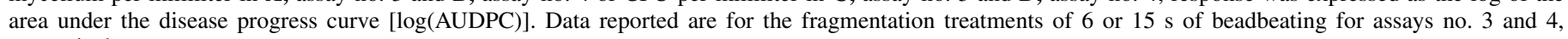
respectively. 
The analyses conducted thus far did not address completely the issue of the influence of CFU within single MYC levels in assays no. 3 and 4 . Thus, using equation 6 , we tested this hypothesis by modeling AUDPC scores as a function of CFU within each MYC level (Table 8). Analyses of data from assay no. 3 indicated that CFU generally had little or no significant explanatory ability on the AUDPC score when mycelium concentration was kept constant. In assay no. 4, within the mycelium concentrations of 60 and $180 \mathrm{mg} / \mathrm{ml}$, CFU was a significant predictor of AUDPC $(P<$ 0.001 and $P=0.002$, respectively) with adjusted $R^{2}$ s of 0.787 and 0.723 , respectively. These results suggested a significant influence of the fragmentation process on the outcome of the virulence assay (Fig. 1C). However, this result was not due to an overall trend of the data but to a high leverage of the AUDPC scores obtained with the lowest CFU concentration (data not shown). When these data were excluded from the fitting, CFU lost any predictive ability (data not shown).

\section{DISCUSSION}

Intrinsic biological features contributed by both the plant and fungus complicate the study of the $M$. fijiensis-banana pathosystem. One significant bottleneck has been the lack of an established methodology for the reliable and practical comparison of virulence levels of multiple isolates of the fungus, including those that are nonnative or genetically modified and, therefore, require biological containment. This is particularly problematic when the number of fungal strains to be tested in replicate exceeds $\approx 10$. A considerable increase in the throughput of assays was achieved here by (i) applying fragmented mycelia as inocula, rather than conidia, and (ii) inoculating each leaf with several M. fijiensis strains. The method reported is the first to validate the reproducibility and reliability of virulence assays in which mycelial fragments are used as the source of inoculum.

We have demonstrated that the use of fragmented mycelia provides a dose-dependent development of disease symptoms for four isolates of $M$. fijiensis. This dose-dependent response is relatively insensitive to the degree of fragmentation of the mycelium and, consequently, the amount of inoculum used for the assay can be measured reliably as a weight. Consistent infection rates were obtained by applying $60 \mu \mathrm{l}$ of a mycelium suspension of $60 \mathrm{mg} / \mathrm{ml}$, fragmented with $10 \mathrm{~s}$ of beadbeating as described for assays no. 1 and 2, to each 5-by-5-cm inoculation site. This amount of mycelium corresponds to $\approx 0.18 \mathrm{mg} / \mathrm{cm}^{2}$, but amounts as low as $20 \mathrm{mg} / \mathrm{ml}\left(\approx 0.06 \mathrm{mg} / \mathrm{cm}^{2}\right)$ also were sufficient (data not shown).

The adequacy of MYC as a measure of inoculum levels can be inferred by closely comparing the origin of the discrepancy in the GLM analysis outcomes for assays no. 3 and 4. These discrepancies can be summarized as follows: (i) in assay no. 3, MYC

TABLE 4. CFU counts (average) of fragmented mycelium of Mycosphaerella fijiensis strain 743 used for assays no. 3 and 4

\begin{tabular}{|c|c|c|c|c|c|c|}
\hline \multirow[b]{2}{*}{ Mycelium (mg/ml) } & \multicolumn{3}{|c|}{ Assay no. $3^{a}$} & \multicolumn{3}{|c|}{ Assay no. $4^{\mathrm{a}}$} \\
\hline & Intensity (s) & $\mathrm{CFU} / \mathrm{ml}$ & SD & Intensity (s) & $\mathrm{CFU} / \mathrm{ml}$ & SD \\
\hline 180 & $10 \mathrm{NB}$ & 206,667 & 40,067 & $10 \mathrm{~V}$ & 51,894 & 10,812 \\
\hline 180 & $1 \mathrm{~B}$ & 63,333 & 11,240 & $5 \mathrm{~B}$ & 517,677 & 97,705 \\
\hline 180 & $3 \mathrm{~B}$ & 83,333 & 18,583 & $10 \mathrm{~B}$ & $1,133,838$ & 115,722 \\
\hline 180 & $6 \mathrm{~B}$ & 266,333 & 54,721 & $15 \mathrm{~B}$ & $1,780,303$ & 124,020 \\
\hline 60 & $10 \mathrm{NB}$ & 48,333 & 8,694 & $10 \mathrm{~V}$ & 43,939 & 9,175 \\
\hline 60 & $1 \mathrm{~B}$ & 23,333 & 2,843 & $5 \mathrm{~B}$ & 428,030 & 46,904 \\
\hline 60 & $3 \mathrm{~B}$ & 30,000 & 6,614 & $10 \mathrm{~B}$ & $1,252,525$ & 190,200 \\
\hline 60 & $6 \mathrm{~B}$ & 26,667 & 4,041 & $15 \mathrm{~B}$ & $1,338,384$ & 171,810 \\
\hline 12 & $10 \mathrm{NB}$ & 3,000 & 600 & $10 \mathrm{~V}$ & 48,864 & 14,761 \\
\hline 12 & $1 \mathrm{~B}$ & 1,000 & 173 & $5 \mathrm{~B}$ & 509,470 & 83,991 \\
\hline 12 & $3 \mathrm{~B}$ & 2,000 & 346 & $10 \mathrm{~B}$ & 556,818 & 144,470 \\
\hline 12 & $6 \mathrm{~B}$ & 6,000 & 1,308 & $15 \mathrm{~B}$ & 588,384 & 66,189 \\
\hline
\end{tabular}

${ }^{a}$ Fragmentation intensity in seconds, $\mathrm{SD}=$ standard deviation, $\mathrm{NB}=$ fragmented without beads, $\mathrm{B}=$ fragmented with beads, and $\mathrm{V}=$ vortexed with beads.

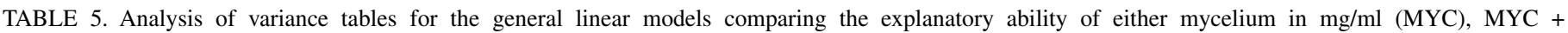
fragmentation, or fragmentation alone of Mycosphaerella fijiensis on Log(CFU) for assays no. 3 and 4

\begin{tabular}{|c|c|c|c|c|c|c|c|c|c|c|c|c|c|c|c|}
\hline \multirow[b]{2}{*}{ Source $^{\mathrm{a}}$} & \multicolumn{5}{|c|}{ MYC + Fragmentation ${ }^{\mathrm{b}}$} & \multicolumn{5}{|c|}{ Fragmentation $^{\mathrm{b}}$} & \multicolumn{5}{|c|}{$\mathrm{MYC}^{\mathrm{b}}$} \\
\hline & SS & $\mathrm{df}$ & MS & $F$ & $P$ & SS & df & MS & $F$ & $P$ & SS & df & MS & $F$ & $P$ \\
\hline \multicolumn{16}{|l|}{ Assay no. 3} \\
\hline Corr. model & $19.695^{\mathrm{c}}$ & 4 & 4.924 & 262.414 & 0.000 & $1.404^{\mathrm{d}}$ & 3 & 0.468 & 0.793 & 0.507 & $18.291^{\mathrm{e}}$ & 1 & 18.291 & 313.266 & 0.000 \\
\hline Intercept & 8.828 & 1 & 8.828 & 470.509 & 0.000 & 675.383 & 1 & 675.383 & $1,145.133$ & 0.000 & 8.828 & 1 & 8.828 & 151.197 & 0.000 \\
\hline $\log (\mathrm{MYC})$ & 18.291 & 1 & 18.291 & 974.851 & 0.000 & $\ldots$ & $\ldots$ & $\ldots$ & $\ldots$ & $\ldots$ & 18.291 & 1 & 18.291 & 313.266 & 0.000 \\
\hline Frag. & 1.404 & 3 & 0.468 & 24.935 & 0.000 & 1.404 & 3 & 0.468 & 0.793 & 0.507 & $\ldots$ & $\ldots$ & $\ldots$ & $\ldots$ & $\ldots$ \\
\hline Error & 0.582 & 31 & 0.019 & $\ldots$ & $\ldots$ & 18.873 & 32 & 0.590 & $\ldots$ & $\ldots$ & 1.985 & 34 & 0.058 & $\ldots$ & $\ldots$ \\
\hline Total & 695.659 & 36 & $\ldots$ & $\ldots$ & $\ldots$ & 695.659 & 36 & $\ldots$ & $\ldots$ & $\ldots$ & 695.659 & 36 & $\ldots$ & $\ldots$ & $\ldots$ \\
\hline \multicolumn{16}{|l|}{ Assay no. 4} \\
\hline Corr. model & $10.926^{\mathrm{f}}$ & 4 & 2.732 & 241.078 & 0.000 & $10.662^{\mathrm{g}}$ & 3 & 3.554 & 184.684 & 0.000 & $0.265^{\mathrm{h}}$ & 1 & 0.265 & 0.817 & 0.373 \\
\hline Intercept & 74.980 & 1 & 74.980 & $6,617.600$ & 0.000 & $1,127.094$ & 1 & $1,127.094$ & $58,571.827$ & 0.000 & 74.980 & 1 & 74.980 & 231.488 & 0.000 \\
\hline $\log (\mathrm{MYC})$ & 10.662 & 1 & 3.554 & 313.655 & 0.000 & $\ldots$ & $\ldots$ & $\ldots$ & $\ldots$ & $\ldots$ & 0.265 & 1 & 0.265 & 0.817 & 0.373 \\
\hline Frag. & 0.265 & 3 & 0.265 & 23.347 & 0.000 & 10.662 & 3 & 3.554 & 184.684 & 0.000 & $\ldots$ & $\ldots$ & $\ldots$ & $\ldots$ & $\ldots$ \\
\hline Error & 0.351 & 31 & 0.011 & $\ldots$ & $\ldots$ & 0.616 & 32 & 0.019 & $\ldots$ & $\ldots$ & 11.013 & 34 & $\ldots$ & $\ldots$ & $\ldots$ \\
\hline Total & $1,138.371$ & 36 & $\ldots$ & $\ldots$ & $\ldots$ & $1,138.371$ & 36 & $\ldots$ & $\ldots$ & $\ldots$ & $1,138.371$ & 36 & $\ldots$ & $\ldots$ & $\ldots$ \\
\hline
\end{tabular}

${ }^{\text {a }}$ Corr. = corrected and Frag. = fragmentation.

${ }^{\mathrm{b}} \mathrm{SS}=$ sum of squares, MS = mean square.

${ }^{\mathrm{c}} R^{2}=0.972 ;$ Adjusted $R^{2}=0.968$.

${ }^{\mathrm{d}} R^{2}=0.069 ;$ Adjusted $R^{2}=-0.018$

${ }^{\mathrm{e}} R^{2}=0.902 ;$ Adjusted $R^{2}=0.899$.

${ }^{\mathrm{f}} R^{2}=0.969 ;$ Adjusted $R^{2}=0.965$.

${ }^{\mathrm{g}} R^{2}=0.945 ;$ Adjusted $R^{2}=0.940$.

${ }^{\mathrm{h}} R^{2}=0.023$; adjusted $R^{2}=-0.005$. 


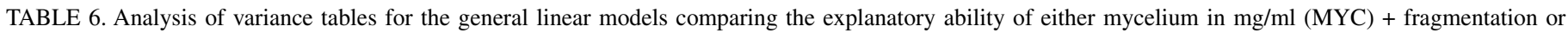
$\mathrm{CFU} / \mathrm{ml}$ (CFU) of Mycosphaerella fijiensis on area under the disease progress curve scores for assays no. 3 and 4

\begin{tabular}{|c|c|c|c|c|c|c|c|c|c|c|}
\hline \multirow[b]{2}{*}{ Source $^{a}$} & \multicolumn{5}{|c|}{$\mathrm{MYC}^{\mathrm{b}}$} & \multicolumn{5}{|c|}{$\mathrm{CFU}^{\mathrm{b}}$} \\
\hline & SS & df & MS & $F$ & $P$ & SS & df & MS & $F$ & $P$ \\
\hline \multicolumn{11}{|l|}{ Assay no. 3} \\
\hline Corrected model & $2.237^{\mathrm{c}}$ & 10 & 0.224 & 10.289 & 0.000 & $2.125^{\mathrm{d}}$ & 4 & 0.531 & 25.124 & 0.000 \\
\hline Intercept & 0.272 & 1 & 0.276 & 12.710 & 0.001 & 0.033 & 1 & 0.033 & 1.578 & 0.218 \\
\hline $\log (\mathrm{MYC})$ & 1.611 & 1 & 1.613 & 74.181 & 0.000 & $\ldots$ & $\ldots$ & $\ldots$ & $\ldots$ & $\ldots$ \\
\hline $\log (\mathrm{CFU})$ & $\ldots$ & $\ldots$ & $\ldots$ & $\ldots$ & $\ldots$ & 1.676 & 1 & 1.676 & 79.290 & 0.000 \\
\hline Frag. & 0.146 & 3 & 0.049 & 2.243 & 0.108 & $\ldots$ & $\ldots$ & $\ldots$ & $\ldots$ & $\ldots$ \\
\hline Frag. $\times \log ($ MYC $)$ & 0.121 & 3 & 0.040 & 1.852 & 0.164 & $\ldots$ & $\ldots$ & $\ldots$ & $\ldots$ & $\ldots$ \\
\hline Plant & 0.135 & 3 & 0.045 & 2.068 & 0.130 & 0.188 & 3 & 0.063 & 2.958 & 0.048 \\
\hline Error & 0.543 & 25 & 0.022 & $\ldots$ & $\ldots$ & 0.655 & 31 & 0.021 & $\ldots$ & $\ldots$ \\
\hline Total & 49.154 & 36 & $\ldots$ & $\ldots$ & $\ldots$ & 49.154 & 36 & $\ldots$ & $\ldots$ & $\ldots$ \\
\hline \multicolumn{11}{|l|}{ Assay no. 4} \\
\hline Corrected model & $2.389^{\mathrm{e}}$ & 9 & 0.265 & 27.710 & 0.000 & $0.766^{\mathrm{f}}$ & 3 & 0.255 & 4.364 & 0.011 \\
\hline Intercept & 0.728 & 1 & 0.728 & 75.966 & 0.000 & 0.001 & 1 & 0.001 & 0.000 & 0.994 \\
\hline $\log (\mathrm{MYC})$ & 1.626 & 1 & 1.626 & 169.683 & 0.000 & $\ldots$ & $\ldots$ & $\ldots$ & $\ldots$ & $\ldots$ \\
\hline $\log (\mathrm{CFU})$ & $\ldots$ & $\ldots$ & $\ldots$ & $\ldots$ & $\ldots$ & 0.579 & 1 & 0.579 & 9.898 & 0.004 \\
\hline Frag. & 0.185 & 3 & 0.062 & 6.448 & 0.002 & $\ldots$ & $\ldots$ & $\ldots$ & $\ldots$ & $\ldots$ \\
\hline Frag. $\times \log (\mathrm{MYC})$ & 0.133 & 3 & 0.044 & 4.644 & 0.010 & $\ldots$ & $\ldots$ & $\ldots$ & $\ldots$ & $\ldots$ \\
\hline Plant & 0.187 & 2 & 0.093 & 9.752 & 0.001 & 0.187 & 2 & 0.093 & 1.597 & 0.218 \\
\hline Error & 0.249 & 26 & 0.010 & $\ldots$ & $\ldots$ & 1.872 & 32 & 0.059 & $\ldots$ & $\ldots$ \\
\hline Total & 60.821 & 36 & $\ldots$ & $\ldots$ & $\ldots$ & 60.821 & 36 & $\ldots$ & $\ldots$ & $\ldots$ \\
\hline
\end{tabular}

${ }^{\mathrm{a}}$ Frag. = fragmentation.

b $\mathrm{SS}=$ sum of squares, MS = mean square.

c $R^{2}=0.805$; adjusted $R^{2}=0.726$.

${ }^{\mathrm{d}} R^{2}=0.764$; adjusted $R^{2}=0.734$.

e $R^{2}=0.906$; adjusted $R^{2}=0.873$.

${ }^{\mathrm{f}} R^{2}=0.290$; adjusted $R^{2}=0.224$.

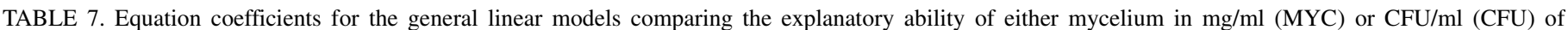
Mycosphaerella fijiensis on area under the disease progress curve scores for assays no. 3 and 4

\begin{tabular}{|c|c|c|c|c|c|c|c|c|}
\hline \multirow[b]{2}{*}{ Parameter $^{\mathrm{a}}$} & \multicolumn{4}{|c|}{$\mathrm{MYC}^{\mathrm{b}}$} & \multicolumn{4}{|c|}{$\mathrm{CFU}^{\mathrm{b}}$} \\
\hline & Value & SE & $t$ & $P$ & Value & SE & $t$ & $P$ \\
\hline \multicolumn{9}{|l|}{ Assay no. 3} \\
\hline$\beta_{0}($ Intercept $)$ & 0.649 & 0.182 & 3.569 & 0.001 & -0.188 & 0.145 & -1.298 & 0.204 \\
\hline$\beta_{1}[\log (\mathrm{MYC})]$ & 0.270 & 0.103 & 2.618 & 0.015 & $\ldots$ & $\ldots$ & $\ldots$ & $\ldots$ \\
\hline$\beta_{1}[\log (\mathrm{CFU})]$ & $\ldots$ & $\ldots$ & $\ldots$ & $\ldots$ & 0.299 & 0.034 & 8.904 & 0.000 \\
\hline$\delta_{11}($ plant no. 1$)$ & 0.103 & 0.071 & 1.454 & 0.156 & 0.098 & 0.068 & 1.453 & 0.156 \\
\hline$\delta_{12}$ (plant no. 2$)$ & -0.108 & 0.088 & -1.233 & 0.227 & -0.125 & 0.084 & -1.496 & 0.145 \\
\hline$\delta_{13}($ plant no. 3$)$ & 0.075 & 0.072 & 1.036 & 0.308 & 0.043 & 0.069 & 0.626 & 0.536 \\
\hline$\delta_{14}($ plant no. 4$)$ & $0^{\mathrm{c}}$ & $\ldots$ & $\ldots$ & $\ldots$ & $0^{\mathrm{c}}$ & $\ldots$ & $\ldots$ & $\ldots$ \\
\hline$\delta_{21}(6 \mathrm{~s} \mathrm{~B})$ & -0.270 & 0.257 & -1.051 & 0.303 & $\cdots$ & $\cdots$ & $\cdots$ & $\cdots$ \\
\hline$\delta_{22}(3 \mathrm{~s} \mathrm{~B})$ & -0.505 & 0.256 & -1.969 & 0.060 & $\ldots$ & $\ldots$ & $\ldots$ & $\ldots$ \\
\hline$\delta_{23}(1 \mathrm{~s} \mathrm{~B})$ & -0.627 & 0.261 & -2.401 & 0.024 & $\ldots$ & $\ldots$ & $\ldots$ & $\ldots$ \\
\hline$\delta_{24}(10 \mathrm{~s} \mathrm{NB})$ & $0^{\mathrm{c}}$ & $\ldots$ & $\ldots$ & $\ldots$ & $\ldots$ & $\ldots$ & $\ldots$ & $\ldots$ \\
\hline$\delta_{31}[6 \mathrm{~s} \mathrm{~B} \times \log (\mathrm{MYC})]$ & 0.158 & 0.145 & 1.090 & 0.286 & $\ldots$ & $\ldots$ & $\ldots$ & $\ldots$ \\
\hline$\delta_{32}[3 \mathrm{~s} \mathrm{~B} \times \log (\mathrm{MYC})]$ & 0.283 & 0.145 & 1.951 & 0.062 & $\ldots$ & $\ldots$ & $\ldots$ & $\ldots$ \\
\hline$\delta_{33}[1 \mathrm{~s} \mathrm{~B} \times \log (\mathrm{MYC})]$ & 0.310 & 0.147 & 2.105 & 0.045 & $\ldots$ & $\ldots$ & $\ldots$ & $\ldots$ \\
\hline$\delta_{34}[10 \mathrm{~s} N B \times \log (\mathrm{MYC})]$ & $0^{\mathrm{c}}$ & $\cdots$ & $\cdots$ & $\cdots$ & $\cdots$ & $\cdots$ & $\cdots$ & $\cdots$ \\
\hline \multicolumn{9}{|l|}{ Assay no. 4} \\
\hline$\beta_{0}($ Intercept $)$ & 0.398 & 0.122 & 3.267 & 0.003 & -0.042 & 0.409 & -0.102 & 0.920 \\
\hline$\beta_{1}[\log (\mathrm{MYC})]$ & 0.389 & 0.068 & 5.758 & 0.000 & $\ldots$ & $\ldots$ & $\ldots$ & $\ldots$ \\
\hline$\beta_{1}[\log (\mathrm{CFU})]$ & $\ldots$ & $\ldots$ & $\ldots$ & $\ldots$ & 0.227 & 0.072 & 3.146 & 0.004 \\
\hline$\delta_{11}($ plant no. 1$)$ & -0.012 & 0.040 & -0.297 & 0.769 & -0.012 & 0.099 & -0.120 & 0.905 \\
\hline$\delta_{12}($ plant no. 2$)$ & 0.147 & 0.040 & 3.668 & 0.001 & 0.147 & 0.099 & 1.484 & 0.148 \\
\hline$\delta_{13}($ plant no. 3$)$ & $0^{c}$ & $\ldots$ & $\ldots$ & $\ldots$ & $0^{c}$ & $\ldots$ & $\ldots$ & $\ldots$ \\
\hline$\delta_{21}(15 \mathrm{~s} \mathrm{~B})$ & 0.039 & 0.169 & 0.233 & 0.818 & $\cdots$ & $\cdots$ & $\cdots$ & $\cdots$ \\
\hline$\delta_{22}(10 \mathrm{~s} \mathrm{~B})$ & -0.225 & 0.169 & -1.330 & 0.195 & $\ldots$ & $\ldots$ & $\ldots$ & $\ldots$ \\
\hline$\delta_{23}(5 \mathrm{~s} \mathrm{~B})$ & 0.499 & 0.169 & 2.951 & 0.007 & $\cdots$ & $\cdots$ & $\cdots$ & $\cdots$ \\
\hline$\delta_{24}(10 \mathrm{~s} \mathrm{~V})$ & $0^{c}$ & $\ldots$ & $\ldots$ & $\ldots$ & $\ldots$ & $\ldots$ & $\ldots$ & $\ldots$ \\
\hline$\delta_{31}[15 \mathrm{~s} \mathrm{~B} \times \log (\mathrm{MYC})]$ & 0.120 & 0.096 & 1.261 & 0.219 & $\cdots$ & $\cdots$ & $\cdots$ & $\cdots$ \\
\hline$\delta_{32}[10 \mathrm{~s} \mathrm{~B} \times \log (\mathrm{MYC})]$ & 0.209 & 0.096 & 2.189 & 0.038 & $\ldots$ & $\ldots$ & $\ldots$ & $\ldots$ \\
\hline$\delta_{33}[5 \mathrm{~s} \mathrm{~B} \times \log (\mathrm{MYC})]$ & -0.125 & 0.096 & -1.313 & 0.201 & $\ldots$ & $\ldots$ & $\ldots$ & $\ldots$ \\
\hline$\delta_{34}[10 \mathrm{~s} \mathrm{~V} \times \log (\mathrm{MYC})]$ & $0^{\mathrm{c}}$ & $\ldots$ & $\ldots$ & $\ldots$ & $\ldots$ & $\ldots$ & $\ldots$ & $\ldots$ \\
\hline
\end{tabular}

${ }^{a} \mathrm{NB}=$ fragmented without beads, $\mathrm{B}=$ fragmented with beads, and $\mathrm{V}=$ vortexed with beads.

b Value = parameter value and $\mathrm{SE}=$ standard error.

c This parameter is set to zero because it was used as the reference. 
and CFU behaved similarly as predictors of AUDPC whereas, in assay no. 4, MYC performed significantly better than CFU; (ii) in assay no. 3, the fragmentation treatment was an insignificant explanatory variable for AUDPC whereas, in assay no. 4, the opposite was true; (iii) in assay no. 3, MYC explained a significant fraction of CFU variability whereas, in assay no. 4, that factor was not significant; and (iv) in assay no. 3, differences in CFU levels could not be explained as being due to the effect of the fragmentation process whereas, in assay no. 4, the opposite was the case. These observations indicate that expected CFU levels depend on both the amount of mycelium and the beadbeating intensity, and that the relative importance of these two factors varies greatly from assay to assay. When the fragmentation process was not effective, as in assay no. 3, CFU levels were strongly dependent on MYC levels and, consequently, they both represented the same entity (i.e. the amount of fungal biomass). In this case, CFU and MYC performed similarly in explaining AUDPC variability. When the fragmentation process was very effective, as in assay no. 4, CFU levels were largely dependent on the fragmentation process, and different mycelium weights generated similar numbers of CFU. In this case, CFU lost the ability to explain AUDPC levels.

These analyses demonstrate that MYC is better than CFU in explaining AUDPC variability because MYC is a less ambiguous way of quantifying the amount of fungal biomass used as inoculum. Furthermore, CFU assessment is time consuming, and the data cannot be collected until $\approx 1$ week after plants have been inoculated. Because CFU levels also can depend on MYC levels, CFU was not a reliable predictor of the effect of the degree of fragmentation on AUDPC. The inadequacy of CFU as a predictor of AUDPC was further confirmed when AUDPC variability could not be explained by CFU levels when MYC was kept constant. The only exception to the lack of CFU influence on AUDPC was when inoculations with mycelia producing high CFU concentrations were compared with those in which CFU yield was very low, as observed for the inoculum obtained by vortexing in assay no. 4.

The causes of the high variability in fragmentation levels from one experiment to the next, even within the same strain, are unknown. Some possible sources of this variability are differences in size and shape of the mycelium fragments scraped from culture plates and small inconsistencies in the amounts of beads used for fragmentation. It is also notable that $M$. fijiensis strains with pigmentation deficiencies tended to fragment more efficiently than those that are highly melanized, as are typical wild-type strains.

Our mycelium-based approach for banana leaf inoculations provided the expected discrimination of the relative virulence of isolates 301 and 743, demonstrating its reliability. AUDPC scores and symptom development for these strains resulted in conclusions comparable with those obtained by Fullerton and Olsen (20), who also assayed symptom development of the same strains on juvenile plants of the banana cv. Grande Naine. Our results are encouraging given that Fullerton and Olsen used significantly different inoculation conditions than we did, and yet our determination of relative virulence levels was directly comparable with theirs. Specifically, they screened strains of M. fijiensis on Musa genotypes using in vitro-produced conidia sprayed on the abaxial surface (R. A. Fullerton, personal communication) of young leaves (15 to $25 \mathrm{~cm}$ long) of tissue-culture-derived potted plants, which then were incubated under high-humidity conditions at 25 to $28^{\circ} \mathrm{C}$. They concluded that strains 743 (Fullerton \#298) and 301 (Fullerton \#722) gave grades 5 (very high virulence) and 4 (high virulence) reactions, respectively, on Grande Naine. Similarly, in all virulence assays conducted in our laboratory, 743 was always more aggressive than 301. Furthermore, Fullerton and Olson (20) demonstrated on a set of reference Musa hosts, representing a range of susceptibilities to $M$. fijiensis, that 743 was highly virulent (grade 4 or 5) on 93\% (13 of 14) of the Musa genotypes tested, whereas 301 was highly virulent on only $64 \%$ (7 of 11), suggesting that 301 generally is less virulent than 743 across a range of plant genotypes.

Using fragmented mycelia as inocula, we also could assess the virulence of strain 743Pink, which is derived from strain 743 but differs by being deficient in conidia production and displaying a distinctive pink pigmentation. Strain 743Pink is particularly interesting because it is capable of penetrating banana leaf tissue, but the infection is blocked at very early stages (data not shown), and the small necrotic specks it consistently produces on plants are suggestive of a hypersensitive response. This is the first report for any Mycosphaerella banana pathogen that demonstrates a clear quantitative difference in virulence between a wild-type isolate and an isogenic mutant derived from that isolate. As such, 743Pink will be a valuable tool for the study of $M$. fijiensis

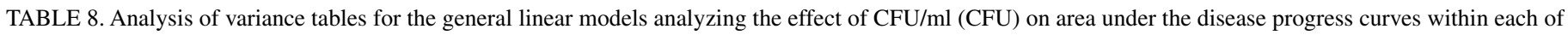
three concentrations of fragmented mycelium of Mycosphaerella fijiensis used for assays no. 3 and 4

\begin{tabular}{|c|c|c|c|c|c|c|c|c|c|c|c|c|c|c|c|}
\hline \multirow[b]{2}{*}{ Source $^{\mathrm{a}}$} & \multicolumn{5}{|c|}{$12 \mathrm{mg} / \mathrm{ml}^{\mathrm{b}}$} & \multicolumn{5}{|c|}{$60 \mathrm{mg} / \mathrm{ml}^{\mathrm{b}}$} & \multicolumn{5}{|c|}{$180 \mathrm{mg} / \mathrm{ml}^{\mathrm{b}}$} \\
\hline & SS & df & MS & $F$ & $P$ & SS & df & MS & $F$ & $P$ & SS & $\mathrm{df}$ & MS & $F$ & $P$ \\
\hline \multicolumn{16}{|l|}{ Assay no. 3} \\
\hline Corr. mod. & $0.279^{c}$ & 4 & 0.070 & 2.657 & 0.123 & $0.089^{\mathrm{d}}$ & 4 & 0.022 & 0.507 & 0.733 & $0.006^{\mathrm{e}}$ & 4 & 0.002 & 0.257 & 0.897 \\
\hline Intercept & 0.002 & 1 & 0.002 & 0.077 & 0.790 & 0.009 & 1 & 0.009 & 0.212 & 0.660 & 2.173 & 1 & 2.173 & 367.368 & 0.000 \\
\hline $\log (\mathrm{CFU})$ & 0.063 & 1 & 0.063 & 2.415 & 0.164 & $<0.001$ & 1 & $<0.001$ & 0.000 & 0.993 & 0.002 & 1 & 0.002 & 0.297 & 0.602 \\
\hline Plant & 0.112 & 3 & 0.037 & 1.421 & 0.315 & 0.086 & 3 & 0.029 & 0.655 & $\ldots$ & 0.004 & 3 & 0.001 & 0.238 & 0.867 \\
\hline Error & 0.184 & 7 & 0.026 & $\ldots$ & $\ldots$ & 0.306 & 7 & 0.044 & $\ldots$ & 0.605 & 0.041 & 7 & 0.006 & $\ldots$ & $\ldots$ \\
\hline Total & 8.905 & 12 & $\ldots$ & $\ldots$ & $\ldots$ & 16.878 & 12 & $\ldots$ & $\ldots$ & $\ldots$ & 23.371 & 12 & $\ldots$ & $\ldots$ & $\ldots$ \\
\hline \multicolumn{16}{|l|}{ Assay no. 4} \\
\hline Corr. mod. & $0.134^{\mathrm{f}}$ & 3 & 0.045 & 1.169 & 0.380 & $0.400^{\mathrm{g}}$ & 3 & 0.133 & 14.559 & 0.001 & $0.079^{\mathrm{h}}$ & 3 & 0.026 & 10.562 & 0.004 \\
\hline Intercept & 0.021 & 1 & 0.021 & 0.561 & 0.475 & 0.010 & 1 & 0.010 & 1.054 & 0.335 & 0.097 & 1 & 0.097 & 39.008 & 0.000 \\
\hline $\log (\mathrm{CFU})$ & 0.020 & 1 & 0.020 & 0.523 & 0.490 & 0.337 & 1 & 0.337 & 36.767 & 0.001 & 0.053 & 1 & 0.053 & 21.219 & 0.002 \\
\hline Plant & 0.114 & 2 & 0.057 & 1.492 & 0.281 & 0.063 & 2 & 0.032 & 3.456 & 0.083 & 0.026 & 2 & 0.013 & 5.233 & 0.035 \\
\hline Error & 0.306 & 8 & 0.038 & $\ldots$ & $\ldots$ & 0.073 & 8 & 0.009 & $\ldots$ & $\ldots$ & 0.020 & 8 & 0.002 & $\ldots$ & $\ldots$ \\
\hline Total & 12.409 & 12 & $\ldots$ & $\ldots$ & $\ldots$ & 20.685 & 12 & $\ldots$ & $\ldots$ & $\ldots$ & 27.727 & 12 & $\ldots$ & $\ldots$ & $\ldots$ \\
\hline
\end{tabular}

a Corr. mod. = corrected model.

${ }^{\mathrm{b}} \mathrm{SS}=$ sum of squares, $\mathrm{MS}=$ mean square.

${ }^{\mathrm{c}} R^{2}=0.603 ;$ adjusted $R^{2}=0.379$.

d $R^{2}=0.225$; adjusted $R^{2}=-0.218$.

e $R^{2}=0.128$; adjusted $R^{2}=-0.370$.

${ }^{\text {f }} R^{2}=0.305$; adjusted $R^{2}=0.044$.

g $R^{2}=0.845$; adjusted $R^{2}=0.787$.

h $R^{2}=0.798$; adjusted $R^{2}=0.723$. 
pathogenicity and banana resistance mechanisms at the molecular level. The second pigmentation mutant tested in this study was strain 301W2.2. Unlike strain 743Pink, 301W2.2 is capable of abundant conidiation, and its ability to cause disease was comparable with that of the parent strain 301 .

Most methods currently in use for assessing disease severity of Mycosphaerella pathogens of bananas involve grading systems or scales that require some degree of subjectivity or do not lend themselves to robust statistical analyses. These systems have been reviewed in Fouré et al. (19). Current methods for evaluation of Musa spp. performance in response to pathogens and pests are summarized in Carlier et al. (13). However, none of these methods provides a direct measure of the damage caused by Mycosphaerella spp. on individually replicated leaves under controlled laboratory conditions for the purpose of identifying statistically relevant differences between fungal isolates and hosts in disease development over time.

On some occasions, we observed significant variability in the timing of disease symptoms. For example, in assay no. 4, disease intensity peaked at 65 to 70 days after inoculation with mycelium at $180 \mathrm{mg} / \mathrm{ml}$ (Fig. 1C) compared with 49 days in assay no. 3 (Fig. 1D) after applying the same amount of inoculum. This result most likely was due to differences in plant or leaf physiology and response. Assays no. 3 and 4 were not planned to take into account the plant as a source of variability. However, unanticipated differences in plant response in these assays forced us to include the plant among the factors in equations 4 and 5 during the data analysis stage. The origin of the difference among plants is not known. However, it could be related to differences in plant age of only a few weeks and potential exposures to unknown stressors during growth in tissue culture or the potting constraints imposed during growth under greenhouse or growth-chamber conditions. Additionally, plants may respond differentially to the sudden change of conditions from the relatively dry, low-light conditions of the greenhouse to the artificially illuminated and very humid growth chamber used for virulence assays.

Another source of variability in early experiments was from inconsistencies in the application of inocula. Making aliquots of the suspensions intended for each inoculation site rather than sampling the inoculum for each replicate from the same tube solved this problem. Jones (28) also noted significant levels of variability in disease response in juvenile plants of some cultivars, even when key parameters such as size of inoculated leaf, mycelium dose $(50 \mathrm{mg} / \mathrm{ml})$, and incubation conditions following inoculation were controlled. Clearly, more studies are required to understand how to limit the additional unknown sources of variability that effect the rate at which Mycosphaerella pathogens invade banana leaf tissues in artificial growth conditions.

In early studies, we observed faster disease response times with younger plants $(<1 \mathrm{~m}$ tall $)$ than with older plants, as reported by others) $(28,62)$, observing symptoms as early as 16 days after inoculation on juvenile plants $\approx 2$ months old (data not shown). However, because fewer isolates could be screened at one time in experiments using the smaller leaves of such plants, we found it advantageous to focus assay development efforts on plants with larger, older leaves. Pasberg-Gauhl (41) demonstrated that disease development on very young tissue-culture plants is different from field-adapted plants. Hence, our strategy of using large leaves of 3- to 6-month-old plants may be more representative of disease development and plant response in established juvenile plants in the field. As observed by others $(25,28,30)$, we found that 2 - to 3 -month-old juvenile plants exhibited streak and spot symptoms that tended to be more circular than elongated (data not shown). In contrast, our inoculated 3- to 6-month-old plants incubated in growth chambers exhibited elongated spots and streaks that were more typical of adult field-infected plants (Fig. 1).

We observed first symptoms on Grande Naine leaves at 25 or 35 days after inoculation for assays no. 1 and 2, respectively. In the field, under conditions of natural infestation, the time between infection and the first appearance of symptoms on a new leaf emerging from the apex of the pseudostem is termed the "incubation period" $(23,53)$. Depending on weather conditions and plant susceptibility (33), the incubation period on susceptible cultivars can be as short as 10 to 14 days under moist, favorable conditions or as long as 35 days under dry, less favorable conditions $(23,29)$. The incubation period for susceptible juvenile plants artificially inoculated with $M$. fijiensis and held in greenhouses or growth chambers is between 12 and 21 days, with an apparent average of $\approx 16$ days $(1,24,26,37,38)$. The relatively longer incubation period observed in this study in comparison with other artificial inoculations reported in the literature likely is due to our use of older and larger leaves to increase the number of strains assayed within a single experiment. Nevertheless, our incubation periods are directly comparable with those reported by Pasberg-Gauhl (41) for 3- to 8-month-old juvenile, tissue-culturederived Musa spp. grown in the field under conditions of natural infestation. Others have demonstrated that the incubation period is faster on 3- to 5-month old plants derived from tissue culture than on field-established plants (23), further supporting the validity of using larger, older leaves for assaying relative virulence and susceptibility in the M. fijiensis-Musa spp. pathosystem.

Jacome and Schuh $(24,25)$ determined that older leaves $(\approx 24$ to 32 days post emergence at inoculation) were more conducive to disease development than younger leaves $(\approx 8$ to 23 days postemergence), whereas others have reported the opposite (29). Furthermore, researchers have reported that some genotypes of juvenile banana plants appear more susceptible to Mycosphaerella pathogens than their respective adult, field-grown plants $(1,20$, 28 ), suggesting potential value in conducting virulence assays on 3- to 6-month-old plants, as reported here.

In conclusion, the use of weighed, fragmented mycelia as inocula brushed onto defined areas of the abaxial surface of large banana leaves is a reliable way to measure dose and evaluate relative virulence levels of $M$. fijiensis with the aid of image analysis software. The use of fragmented mycelia as inocula has several advantages over that of conidia. These include the reliability and reduced time needed to generate and prepare mycelial inoculum versus spores, and the ability to assess the virulence of isolates that sporulate poorly in vitro. Furthermore, we significantly increased the throughput of $M$. fijiensis pathogenicity assays by shifting from the generally adopted strategy of one strain per plant to multiple strains per leaf. When the inoculation area is reduced further in size, this strategy will allow the evaluation of 100 or more strains per plant (data not shown). At any location where nonnative or genetically engineered isolates are being evaluated in plant assays, biocontainment of such isolates is required, and an inoculation method, such as paint brush application, that is designed to prevent aerosolization of inocula is preferred. Finally, reliable BLSD development outside of the tropics requires the use of environmental growth chambers with specialized lighting and humidity controls, availability of which is often a critical limiting factor, requiring efficacious use of growth-chamber space for pathogenicity assays as described here. These methods will be of value for evaluating Mycosphaerella pathogen virulence, as well as Musa spp. susceptibility, in a broad range of settings where direct, quantitative measures over the full course of symptom development are necessary.

\section{ACKNOWLEDGMENTS}

Funding for this project was from Syngenta Corp. (Bracknell, Berks, UK). We gratefully thank R. Dabrowska, N. Krause, H. McLane, and BTI Greenhouse Staff (Boyce Thompson Institute) for technical assistance in support of this project; J. D. Vandenberg (United States Department of Agriculture-Agricultural Research Service [USDA-ARS], Ithaca, NY) and statisticians at Cornell University's Office of Statistical Consulting 
for statistical advice; J. Van Eck (Boyce Thompson Institute) for advice regarding banana tissue culture; P. Balint-Kurti (USDA-ARS, Raleigh, NC) for early provision of Grande Naine plantlets and isolation of the original 301W mutant; J. Carlier and X. Mourichon (CIRAD, Montpellier, France) for provision of wild-type fungus cultures; and C. Bird, G. Nisbet (Syngenta, Bracknell, Berks, UK), and M. Stuiver (SyngentaMogen, Leiden, The Netherlands) for valuable discussions.

\section{LITERATURE CITED}

1. Alvarado-Capó, Y., Leiva-Mora, M., Dita-Rodríquez, M. A., Acosta, M., Cruz, M., Portal, N., Gómez-Kosky, R., García, L., Bermúdez, I., and Padrón, J. 2003. Early evaluation of black leaf streak resistance by using mycelial suspensions of Mycosphaerella fijiensis. Pages 169-175 in: Mycosphaerella Leaf Spot Diseases of Bananas: Present Status and Outlook. Proc. 2nd Int. Workshop on Mycosphaerella Leaf Spot Diseases, San José, Costa Rica. L. Jacome, P. Lepoivre, D. Marin, R. Ortiz, R. Romero, and J. V. Escalant, eds. The International Network for the Improvement of Banana and Plantain, Montpellier, France.

2. Anonymous. 1993. Fungicide Resistance Action Committee (FRAC) Banana Working Group. Conclusions and Recommendations of the Third Meeting. Orlando, FL.

3. Arias, P., Dankers, C., Liu, P., and Pilkauskas, P. 2003. The World Banana Economy, 1985-2002. FAO Commodity Studies 1. Food and Agriculture Organization of the United Nations, Rome.

4. Arraiano, L. S., Brading, P. A., and Brown, J. K. M. 2001. A detached seedling leaf technique to study resistance to Mycosphaerella graminicola (anamorph Septoria tritici) in wheat. Plant Pathol. 50:339-346.

5. Balint-Kurti, P. J., May, G. D., and Churchill, A. C. L. 2001. Development of a transformation system for Mycosphaerella pathogens of banana: a tool for the study of host/pathogen interactions. FEMS Microbiol. Lett. 195:9-15.

6. Berruyer, R., Poussier, S., Kankanala, P., Mosquera, G., and Valent, B. 2006. Quantitative and qualitative influence of inoculation methods on in planta growth of rice blast fungus. Phytopathology 96:346-355.

7. Bradshaw, R. E., Ganley, R. J., Jones, W. T., and Dyer, P. S. 2000. High levels of dothistromin toxin produced by the forest pathogen Dothistroma pini. Mycol. Res. 104:325-332.

8. Brown, M. V., Moore, J. N., Fenn, P., and McNew, R. W. 1999. Comparison of leaf disk, greenhouse, and field screening procedures for evaluation of grape seedlings for downy mildew resistance. HortScience 34:331-333.

9. Browne, R. A., Murphy, J. P., Cooke, B. M., Devaney, D., Walsh, E. J., Griffey, C. A., Hancock, J. A., Harrison, S. A., Hart, P., Kolb, F. L., McKendry, A. L., Milus, E. A., Sneller, C., and Sanford, D. A. V. 2005. Evaluation of components of Fusarium head blight resistance in soft red winter wheat germ plasm using a detached leaf assay. Plant Dis. 89:404411.

10. Campbell, C. L., and Madden, L. V. 1990. Introduction to Plant Disease Epidemiology. John Wiley, New York.

11. Carlier, J., Fouré, E., Gauhl, F., Jones, D. R., Lepoivre, P., Mourichon, X., Pasberg-Gauhl, C., and Romero, R. A. 2000. Black leaf streak. Pages 3779 in: Diseases of Banana, Abacá and Enset. D. R. Jones, ed. CABI Publishing, New York.

12. Carlier, J., Waele, D. D., and Escalant, J. V. 2002. Global evaluation of Musa germplasm for resistance to Fusarium wilt, Mycosphaerella leaf spot diseases and nematodes: in-depth evaluation. In: INIBAP Technical Guidelines 6. A. Vézina and C. Picq, eds. The International Network for the Improvement of Banana and Plantain, Montpellier, France.

13. Carlier, J., Waele, D. D., and Escalant, J. V. 2003. Global evaluation of Musa germplasm for resistance to Fusarium wilt, Mycosphaerella leaf spot diseases and nematodes: Performance evaluation. In: INIBAP Technical Guidelines 7. A. Vézina and C. Picq, eds. The International Network for the Improvement of Banana and Plantain, Montpellier, France.

14. Ehlenfeldt, M. K., Polashock, J. J., Stretch, A. W., and Kramer, M. 2006. Leaf disk infection by Colletotrichum acutatum and its relation to fruit rot in diverse blueberry germplasm. HortScience 41:270-271.

15. El Hadrami, A., Zapater, M. F., Lapeyre, F., Mourichon, X., and Carlier, J. 1998. A leaf disk assay to assess partial resistance of banana germplasm and aggressiveness of Mycosphaerella fijiensis, the causal agent of black leaf streak disease. In: 7th Int. Congress Plant Pathol. ICPP98. Edinburgh.

16. Etebu, E., Pasberg-Gauhl, C., Gauhl, F., and Daniel-Kalio, L. A. 2003. Preliminary studies of in vitro stimulation of sexual mating among isolates of Mycosphaerella fijiensis, causal agent of black Sigatoka disease in bananas and plantains. Phytoparasitica 31:69-75.

17. Fouré, E., and Mouliom-Pefoura, A. 1988. La cercosporiose noire des bananiers et des plantains au Cameroun (M. fijiensis). Contribution a l'étude des premières phase de l'infection parasitaire. Mise au point de tests précoces d'inoculation sur plants issus de vitro-culture. Fruits 43:339-348.

18. Fouré, E., Mouliom-Pefoura, A., and Mourichon, X. 1990. Etude de la sensibilité variétale des bananiers et des plantains à Mycosphaerella fijiensis Morelet au Cameroun. Charactérisation de la résistance au champ de bananiers appartenant à divers groupes génétiques. Fruits 45:339-345.

19. Fouré, E., Mourichon, X., and Jones, D. R. 2000. Black leaf streak: Host reaction-evaluating germplasm for reaction to black leaf streak. Pages 62-67 in: Diseases of Banana, Abacá and Enset. D. R. Jones, ed. CABI Publishing, New York.

20. Fullerton, R. A., and Olsen, T. L. 1995. Pathogenic variability in Mycosphaerella fijiensis Morelet, cause of black Sigatoka in banana and plantain. N. Z. J. Crop Hortic. Sci. 23:39-48.

21. Ganapathi, T. R., Higgs, N. S., Balint-Kurti, P. J., Arntzen, C. J., May, G. D., and Eck, J. M. V. 2001. Agrobacterium-mediated transformation of embryogenic cell suspensions of the banana cultivar Rasthali (AAB). Plant Cell Rep. 20:157-162.

22. Garry, G., Forbes, G. A., Salas, A., Santa Cruz, M., Perez, W. G., and Nelson, R. J. 2005. Genetic diversity and host differentiation among isolates of Phytophthora infestans from cultivated potato and wild solanaceous hosts in Peru. Plant Pathol. 54:740-748.

23. Gauhl, F., Pasberg-Gauhl, C., and Jones, D. R. 2000. Black leaf streak: disease cycle and epidemiology. Pages 56-62 in: Diseases of Banana, Abacá and Enset. D. R. Jones, ed. CABI Publishing, New York.

24. Jacome, L. H., and Schuh, W. 1992. Effects of leaf wetness duration and temperature on development of black Sigatoka disease on banana infected by Mycosphaerella fijiensis var. difformis. Phytopathology 82:515-520.

25. Jacome, L. H., and Schuh, W. 1993. Effect of temperature on growth and conidial production in vitro, and comparison of infection and aggressiveness in vivo among isolates of Mycosphaerella fijiensis var. difformis. Trop. Agric. (Trinidad) 70:51-59.

26. Jacome, L. H., and Schuh, W. 1993. Spore production and artificial inoculation techniques for Mycosphaerella fijiensis var. difformis. Trop. Agric. (Trinidad) 70:33-38.

27. Jones, D. R. 1993. Evaluating banana and plantain for reaction to black leaf streak disease in the South Pacific. Trop. Agric. (Trinidad) 70:39-44.

28. Jones, D. R. 1995. Rapid assessment of Musa for reaction to Sigatoka disease. Fruits 50:11-22.

29. Marín, D. H., Romero, R. A., Guzmán, M., and Sutton, T. B. 2003. Black Sigatoka: An increasing threat to banana cultivation. Plant Dis. 87:208222.

30. McGahan, M. W., and Fulton, F. H. 1965. Leaf spot of bananas caused by Mycosphaerella musicola: A comparative anatomical study of juvenile and adult leaves in relation to lesion morphology. Phytopathology 55:1179-1182.

31. Mercier, J., Howie, W. J., and Balint-Kurti, P. 2001. A detached leaf assay to evaluate the resistance of banana to Mycosphaerella fijiensis. (Abstr.) Phytopathology 91:S61.

32. Meredith, D. S., and Lawrence, J. S. 1969. Black leaf streak disease of bananas (Mycosphaerella fijiensis): symptoms of disease in Hawaii, and notes on the conidial state of the causal fungus. Trans. Br. Mycol. Soc. 52:459-476.

33. Meredith, D. S., and Lawrence, J. S. 1970. Black leaf streak of bananas (Mycosphaerella fijiensis): Susceptibility of cultivars. Trop. Agric. (Trinidad) 47:275-287.

34. Mobambo, K. N., Gauhl, F., Pasberg-Gauhl, C., and Zuofa, K. 1996. Season and plant age effect evaluation of plantain for response to black Sigatoka disease. Crop Prot. 15:609-614.

35. Mobambo, K. N., Gauhl, F., Vuylsteke, D., Ortiz, R., Pasberg-Gauhl, C., and Swennen, R. 1993. Yield loss in plantain from black Sigatoka leaf spot and field performance of resistant hybrids. Field Crops Res. 35:3542.

36. Mobambo, K. N., Pasberg-Gauhl, C., Gauhl, F., and Zuofa, K. 1997. Host response to black Sigatoka in Musa germplasm of different ages under natural inoculation conditions. Crop Prot. 16:359-363.

37. Mouliom-Pefoura, A., Lassoudière, A., Foko, J., and Fontem, D. A. 1996. Comparison of development of Mycosphaerella fijiensis and Mycosphaerella musicola on banana and plantain in the various ecological zones in Cameroon. Plant Dis. 80:950-954.

38. Mourichon, X., Peter, D., and Zapater, M. F. 1987. Inoculation expérimentale de Mycosphaerella fijiensis Morelet sur de jeunes plantules de bananiers issues de culture in vitro. Fruits 42:195-198.

39. Mourichon, X., and Zapater, M. F. 1990. Obtention in vitro du stade Mycosphaerella fijiensis, forme parfaite de Cercospora fijiensis. Fruits 45:553-557.

40. Olmstead, J. W., Lang, G. A., and Grove, G. G. 2000. A leaf disk assay for screening sweet cherry genotypes for susceptibility to powdery mildew. HortScience 35:274-277.

41. Pasberg-Gauhl, C. 1993. Symptom development of black Sigatoka leaf spot on young or adult banana and plantain plants after natural inocu- 
lation. Pages 263-275 in: Biological and Integrated Control of Highland Banana and Plantain Pest and Diseases. Proc. Res. Coordination Meeting, Cotonou, Benin. C. Gold and B. Gemmill, eds. International Institute of Tropical Agriculture, Ibadan, Nigeria.

42. Pasberg-Gauhl, C., Gauhl, F., and Jones, D. R. 2000. Black leaf streak: Distribution and economic importance. Pages 37-44 in: Diseases of Banana, Abacá and Enset. D. R. Jones, ed. CABI Publishing, New York.

43. Pérez, L., Hernández, A., Hernández, L., and Pérez, M. 2002. Effect of trifloxystrobin and azoxystrobin on the control of black Sigatoka (Mycosphaerella fijiensis Morelet) on banana and plantain. Crop Prot. 21:17-23.

44. Ploetz, R. 2000. Black Sigatoka. Pestic. Outlook 11:19-23.

45. Ploetz, R. C. 2001. Black Sigatoka of banana: The most important disease of a most important fruit. The Plant Health Instructor. DOI: 10.1094/PHII-2001-0126-01.

46. Romero, R. A., and Sutton, T. B. 1997. Reaction of four Musa genotypes at three temperatures to isolates of Mycosphaerella fijiensis from different geographical regions. Plant Dis. 81:1139-1142.

47. Smith, M. C., Rutter, J., Burt, P. J. A., Ramirez, F., and Gonzalez, E. H. 1997. Black Sigatoka disease of banana: spatial and temporal variability in disease development. Ann. Appl. Biol. 131:63-77.

48. Stewart, E. L., Liu, Z., Crous, P. W., and Szabo, L. J. 1999. Phylogenetic relationships among some cercosporoid anamorphs of Mycosphaerella based on rDNA sequence analysis. Mycol. Res. 103:1491-1499.

49. Stover, R. H. 1969. The Mycosphaerella species associated with banana leaf spots. Trop. Agric. (Trinidad) 46:325-332.

50. Stover, R. H. 1971. A proposed international scale for estimating intensity of banana leaf spot (Mycosphaerella musicola Leach). Trop. Agric. (Trinidad) 48:185-196.

51. Stover, R. H. 1972. Banana, Plantain and Abaca Diseases. Commonwealth Mycological Institute, Surrey, UK.
52. Stover, R. H. 1976. Distribution and cultural characteristics of the pathogens causing banana leaf spot. Trop. Agric. (Trinidad) 53:111-114.

53. Stover, R. H. 1980. Sigatoka leaf sports of bananas and plantains. Plant Dis. 64:750-756

54. Stover, R. H. 1983. Effet du Cercospora noir sur les plantains en Amérique centrale. Fruits 38:326-329.

55. Stover, R. H. 1986. Disease management strategies and the survival of the banana industry. Annu. Rev. Phytopathol. 24:83-91.

56. Stover, R. H., and Dickson, J. D. 1970. Leaf spot of bananas caused by Mycosphaerella musicola: methods of measuring spotting prevalence and severity. Trop. Agric. (Trinidad) 47:289-302.

57. Stover, R. H., and Simmons, N. W. 1987. Bananas, 3rd ed. Longman Group UK Ltd., Essex, UK.

58. Townley, A., Foundling, J., Corsten, M., and Pain, N. A. 2001. Mycosphaerella fijiensis disease development in leaves on whole plants and in a detached leaf assay. In: Caribbean Division Meeting of the American Phytopathological Society. Publication no. P-2002-0119-CRA.

59. Twizeyimana, M., Ojiambo, P. S., Tenkouano, A., Ikotun, T., and Bandyopadhyay, R. 2007. Rapid screening of Musa species for resistance to black leaf streak using in vitro plantlets in tubes and detached leaves. Plant Dis. 91:308-314.

60. Vakili, N. G. 1968. Responses of Musa acuminata species and edible cultivars to infection by Mycosphaerella musicola. Trop. Agric. (Trinidad) 45:13-22.

61. Vuylsteke, D. R., Swennen, R. L., and Ortiz, R. 1993. Development and performance of black Sigatoka-resistant tetraploid hybrids of plantain (Musa spp., AAB group). Euphytica 65:33-42.

62. Washington, J. R., Cruz, J., Lopez, F., and Fajardo, M. 1998. Infection studies of Mycosphaerella fijiensis on banana and the control of black Sigatoka with chlorothalonil. Plant Dis. 82:1185-1190. 